\title{
Geostatistical assessment of warm-season precipitation observations in Korea based on the composite precipitation and satellite water vapor data
}

\author{
Sojung Park ${ }^{1,3,4}$, Seon Ki Park ${ }^{1,2,3,4}$, Jeung Whan Lee ${ }^{5}$, and Yunho Park ${ }^{5}$ \\ ${ }^{1}$ Department of Climate and Energy Systems Engineering, Ewha Womans University, Seoul, Republic of Korea \\ ${ }^{2}$ Department of Environmental Science and Engineering, Ewha Womans University, Seoul, Republic of Korea \\ ${ }^{3}$ Severe Storm Research Center, Ewha Womans University, Seoul, Republic of Korea \\ ${ }^{4}$ Center for Climate/Environment Change Prediction Research, Ewha Womans University, Seoul, Republic of Korea \\ ${ }^{5}$ Korea Meteorological Administration, Seoul, Republic of Korea
}

Correspondence: Seon Ki Park (spark@ewha.ac.kr)

Received: 20 February 2018 - Discussion started: 12 March 2018

Revised: 28 May 2018 - Accepted: 6 June 2018 - Published: 27 June 2018

\begin{abstract}
Among the meteorological disasters, heavy rainfalls cause the second largest damage in Korea, following typhoons. To manage the potential disasters due to heavy rainfalls, understanding the observational characteristics of precipitation is of utmost importance. In this study, we investigate the spatial and temporal characteristics of warmseason precipitation in Korea, according to the precipitation types, by conducting the geostatistical analyses such as an autocorrelogram, Moran's $I$ and general $G$ on the composite (radar + station) precipitation data. The $e$-folding distance of precipitation ranges from 15 to $35 \mathrm{~km}$, depending on the spatial distribution, rather than intensity, of precipitation, whereas the $e$-folding time ranges from 1 to $2 \mathrm{~h}$. The directional analyses revealed that the warm-season precipitation systems in Korea, especially those with a high precipitation amount, have high spatial autocorrelations in the southwest-northeast and west-east directions, in association with the frontal rainfalls, convection bands, etc. Furthermore, the cluster versus dispersion patterns and the hot versus cold spots are analyzed through Moran's $I$ and general $G$, respectively. Water vapor, represented by the brightness temperature, from three Himawari- 8 water vapor bands also shows similar characteristics with precipitation but with strong spatial correlation over a much longer distance $(\sim 100 \mathrm{~km})$, possibly due to the continuity of water vapor. We found that, under the $e$-folding-based standard, the current observation network of Korea is sufficient to capture the characteristics of most precipitation systems; however, under a strict stan-
\end{abstract}

dard (e.g., autocorrelation of 0.6), a higher-resolution observation network is essentially required - especially in local areas with frequent heavy rainfalls - depending on the directional features of precipitation systems. Establishing such an observation network based on the characteristics of precipitation enables us to improve monitoring, tracking, and prediction skills of high-impact weather phenomena as well as to enhance the utilization of numerical weather prediction.

\section{Introduction}

Heavy rainfall causes one of the most serious meteorological disasters in Korea. Most precipitation systems in Korea are highly influenced by the East Asian summer monsoon, called Changma in Korean (Riyu et al., 2001; Kim et al., 2002; Lee et al., 2017b), and hence have high seasonal variation; they also show high spatial variation due to complex topographic features (e.g., Ko et al., 2005; Chang and Kwon, 2007; Park and Lee, 2007; In et al., 2014). Since heavy rainfalls including typhoon cause serious damages to both human life and property, improving the their forecast accuracy is of utmost importance. Many studies have been done to improve the quantitative precipitation forecast using numerical weather prediction models and satellite or radar data (e.g., Fritsch et al., 1998; Lee et al., 2006; Kim and Oh, 2010; Feng and Kitzmiller, 2006; Yu et al., 2013). In order to improve the 
forecast accuracy, it is essential to understand the spatial and temporal characteristics as well as the occurrence and development mechanisms of the precipitation systems.

The ground-based rainfall observation data, in Korea, are collected from the automated synoptic observing systems (ASOS), the automatic weather stations (AWS), and the automated agriculture observing system (AAOS). The observation density is about $67 \mathrm{~km}$ for ASOS and approximately $13 \mathrm{~km}$ by including AWS. The agrometeorological observation network consists of 11 AAOS stations (Choi et al., 2015). Based on these precipitation observations, the mesoscale structures of precipitation as well as the hydrologic budgets in Korea have been extensively studied (e.g., Kim and Lee, 2006; Cassardo et al., 2009; Jeong et al., 2012, 2016; Jung and Lee, 2013; Lee et al., 2017a). Capturing the spatiotemporal features of precipitation systems from the observation networks is essential to runoff forecast, especially at the catchment scale and for the flooding cases (Volkmann et al., 2010). Given the limited resources, it is desirable to optimally design the observation networks, which should be efficient in using least amount of available instruments but sufficient in capturing the precipitation characteristics - both amount and spatiotemporal variability. In other words, understanding temporal and spatial characteristics of precipitation is fundamental and essentially required for the establishment of the optimal observation networks (see Ciach and Krajewski, 2006; Volkmann et al., 2010). Moreover, the appropriateness of such observation networks, in analyzing and/or forecasting the precipitation systems, has seldom been assessed.

In this study, we investigate the spatial and temporal characteristics of precipitation in Korea using the geostatistical analysis methods - autocorrelogram, Moran's $I$, and general $G$ (e.g., Ciach and Krajewski, 2006; Schiemann et al., 2011; Emmanuel et al., 2012; Fu et al., 2014). Ciach and Krajewski (2006) estimated the spatial correlation functions in small-scale rainfall, based on rain gauges covering an area of about $3 \mathrm{~km}$ by $3 \mathrm{~km}$ in central Oklahoma. They showed a dependence of the correlogram parameters on the averaging timescale, large differences of the correlograms in the individual storms, and the ambiguities in correlation estimates based on rainfall intensities. Bacchi and Kottegoda (1995) addressed the effects of weather systems, topography, and temporal and spatial scale of observation networks on the spatial distribution of rainfall. Emmanuel et al. (2012) analyzed the characteristics of spatiotemporal variability by rainfall types using a variogram.

In Korea, the spatial and temporal characteristics of precipitation have been reported in several previous studies (e.g., Chang and Kwon, 2007; Hong et al., 2006; Ha et al., 2007; In et al., 2014). Ha et al. (2007) found that the $e$-folding distance and time in correlation coefficients of AWS precipitation ranged from 50 to $110 \mathrm{~km}$ and 1 to $2 \mathrm{~h}$, respectively. In summer, precipitation showed localized features with relatively more precipitation mainly in the western part and southern coastal areas of Korea (Kim et al., 2005; Hong et al.,
2006; In et al., 2014). In et al. (2014) also analyzed the degree of localization in summer precipitation and noted a high locality of rainfalls, i.e., more frequent occurrence of shortlived local precipitation, in July and August. In addition to these studies, we provide further analyses on the variation of spatial correlation associated with the distribution and intensity of precipitation.

Water vapor is also strongly linked to the precipitation system because not only does it become the absolute source of precipitation (Eltahir and Bras, 1996; Park, 1999; Bretherton et al., 2004; Stohl et al., 2008; Gimeno et al., 2012) but also its transport in the lower troposphere provides diabatic heating and hence promotes development of convective precipitation systems (Tompkins, 2001; Trenberth and Stepaniak, 2003a, b; Smith and Yuter, 2010). Therefore, the amount and behavior of water vapor are the crucial factors in the precipitation system. For instance, a large amount of water vapor originated from the adjacent oceans is transported to the East Asian monsoon region through the large-scale monsoon circulations. The origins of water vapor supply can also distinguish the anomalous rainfall patterns (e.g., Zhou and Yu, 2005). Furthermore, about $70 \%$ of precipitation in extratropical cyclones is generated by water vapor already present when the storm formed in the atmosphere (Trenberth, 1999). Hence, we also conduct the spatial and temporal analysis of water vapor to enhance the understanding of precipitation characteristics over Korea and adjacent areas.

This study aims at classifying the precipitation types statistically based on the spatial distribution of precipitation and at identifying the spatial and temporal characteristics of warm-season precipitation in Korea according to the precipitation types via the geostatistical analysis methods, including autocorrelogram, Moran's $I$, and general $G$. Furthermore, we investigate the characteristics of water vapor over the Korean Peninsula associated with the precipitation types, using satellite data. Section 2 describes the data set used for the analyses, and Sect. 3 briefly introduces the geostatistical methods employed in this study. Results and discussions are provided in Sect. 4. Section 5 is devoted to conclusions.

\section{Data description}

We use the precipitation data from weather stations (see Fig. 1) to categorize the precipitation systems. We classify four different precipitation types statistically, based on two criteria: the portion of weather stations with precipitation $(\mathrm{C} 1$; in \%) and the station average precipitation rate $(\mathrm{C} 2$; in $\mathrm{mm} \mathrm{h}^{-1}$ ). In order to determine the threshold values for classifying the precipitation types, we have conducted a preliminary statistical analysis on precipitation events in the period of 2011-2015 (not shown). As the precipitation events occur in a given time period and space interval, our precipitation data are assumed to follow the Poisson distribution, which represents a probability situation of a large number of obser- 
Table 1. Classification of precipitation types with the number of events (in bold).

\begin{tabular}{|c|c|c|c|}
\hline & & \multicolumn{2}{|c|}{ The portion of weather stations with precipitation $(\mathrm{C} 1)$} \\
\hline & & $<20 \%$ & $\geq 20 \%$ \\
\hline \multirow{2}{*}{$\begin{array}{l}\text { The station average } \\
\text { precipitation rate }(\mathrm{C} 2)\end{array}$} & $<3 \mathrm{~mm} \mathrm{~h}^{-1}$ & $\begin{array}{l}\text { Low precipitation at a few points (LPFP) } \\
\mathbf{5 8 5 8}\end{array}$ & $\begin{array}{l}\text { Low precipitation at many points (LPMP) } \\
\mathbf{1 1 5 7}\end{array}$ \\
\hline & $\geq 3 \mathrm{~mm} \mathrm{~h}^{-1}$ & $\begin{array}{l}\text { High precipitation at a few points (HPFP) } \\
\mathbf{9 8 0}\end{array}$ & $\begin{array}{l}\text { High precipitation at many points (HPMP) } \\
\mathbf{5 9 4}\end{array}$ \\
\hline
\end{tabular}

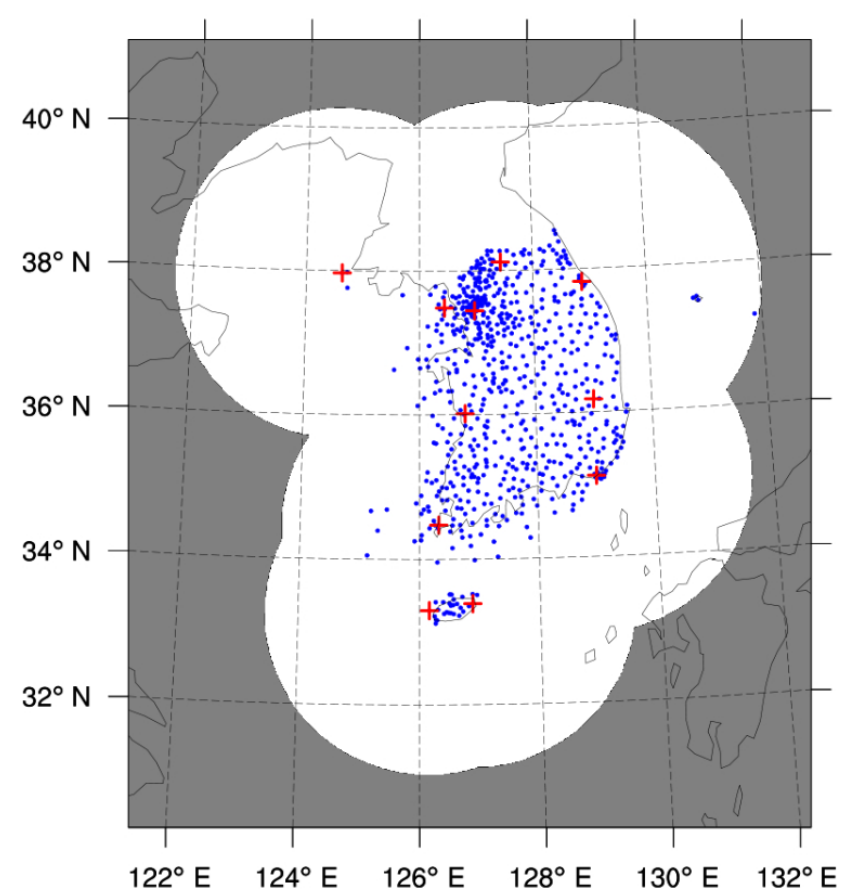

Figure 1. The weather station locations (blue dots) and radar locations (red "+" symbols) and coverages (white area) in Korea.

vations with a small probability of occurrence. Many studies developed the Poisson distribution models to estimate rainfall and to cluster the rainfall systems (e.g., Rodriguez-Iturbe et al., 1987; Lee et al., 2014; Barton et al., 2016; Ritschel et al., 2017). We have chosen the threshold values when the cumulative percentage of precipitation events for each criterion (i.e., $\mathrm{C} 1$ and $\mathrm{C} 2$ ) reached approximately $80 \%$, thus obtaining the threshold values of $20 \%$ for $\mathrm{C} 1$ and $3 \mathrm{~mm} \mathrm{~h}^{-1}$ for $\mathrm{C} 2$, respectively. Our preliminary statistical analysis showed that, in general, most precipitation events occur over small areas and precipitation events with high intensity rarely occur over large areas. The locality of precipitation appeared higher as the precipitation intensity was higher, in accordance with Nam et al. (2014). In particular, precipitation systems with the highest intensity $\left(\geq 10 \mathrm{~mm} \mathrm{~h}^{-1}\right)$ were mostly confined to a small area with the number of stations less than $10 \%$ of total weather stations. This implies that the locality feature of precipitation systems may depend on the threshold value in precipitation intensity.

Based on these criteria, we define four different precipitation types, as shown in Table 1: (1) low precipitation at a few points (LPFP) for $\mathrm{C} 1<20 \%$ and $\mathrm{C} 2<3 \mathrm{~mm} \mathrm{~h}^{-1}$, (2) low precipitation at many points (LPMP) for $\mathrm{C} 1 \geq 20 \%$ and $\mathrm{C} 2<3 \mathrm{~mm} \mathrm{~h}^{-1}$, (3) high precipitation at a few points (HPFP) for $\mathrm{C} 1<20 \%$ and $\mathrm{C} 2 \geq 3 \mathrm{~mm} \mathrm{~h}^{-1}$, and (4) high precipitation at many points (HPMP) for $\mathrm{C} 1 \geq 20 \%$ and $\mathrm{C} 2 \geq 3 \mathrm{~mm} \mathrm{~h}^{-1}$. We practically exclude the LPFP type in our analyses, i.e., the case with $\mathrm{C} 1<20 \%$ and $\mathrm{C} 2<3 \mathrm{~mm} \mathrm{~h}^{-1}$, since it may be less effective.

The Korea Meteorological Administration (KMA) has produced the composite precipitation data over Korea using the data from radars, weather stations, and satellites through the following steps (see Hwang et al., 2015): (1) remove non-precipitation echoes from the radar data using the satellite cloud-type data, (2) calculate the difference between the station precipitation and the radar-estimated precipitation, (3) perform the objective analysis on the precipitation difference field and on the station precipitation data, (4) correct the bias using the objectively analyzed difference field, and (5) combine the corrected radar-estimated precipitation data and the objectively analyzed station precipitation data to produce the composite precipitation data (in $\mathrm{mm} \mathrm{h}^{-1}$ ). In order to analyze the precipitation systems with the evenly distributed high-resolution data, we used these composite precipitation data, which cover $1153 \mathrm{~km} \times 1441 \mathrm{~km}$ over the Korean Peninsula, with a grid size of $1 \mathrm{~km}$ and a time resolution of $1 \mathrm{~h}$. Geostatistical analyses are conducted using the composite precipitation data sets from April to October in the period of 2013-2015 to investigate the spatial and temporal characteristics of warm-season rainfall.

We also used the Himawari- 8 water vapor bands to investigate the distribution feature of water vapor in the lower to upper atmosphere in association with precipitation. The water vapor bands are strongly linked with the properties of moisture, thermodynamics, and dynamics of the troposphere. As they are sensitive to the moisture and temperature profiles in the radiation path, they can provide information for a wide range of atmospheric processes (Georgiev et al., 2016), including atmospheric motions such as the upper-level lows, jet stream, and blocking. Himawari-8, operated by the Japan 
Meteorological Agency since 7 July 2015, carries a new unit called the Advanced Himawari Imager (AHI) with higher radiometric, spectral, and spatial resolution in the geostationary orbit (Bessho et al., 2016). The AHI has 16 observation bands -3 visible $(0.47,0.51,0.64 \mu \mathrm{m}), 3$ near-infrared $(0.86,1.6,2.3 \mu \mathrm{m})$, and 10 infrared $(3.9,6.2,6.9,7.3,8.6$, $9.6,10.4,11.2,12.4,13.3 \mu \mathrm{m})$. Among them the water vapor absorption bands $-8(6.2 \mu \mathrm{m}), 9(6.9 \mu \mathrm{m})$, and $10(7.3 \mu \mathrm{m})$ represent upper-, mid-, and mid- to lower-level water vapor, respectively. The calibration of the Himawari-8 water vapor bands is accurate to within $0.2 \mathrm{~K}$ through a validation approach developed under the Global Space-based InterCalibration System (GSICS) project with hyper-spectral infrared sounders (e.g., Okuyama et al., 2015; Bessho et al., 2016). In this study, we used the scan area for the full disk by the AHI that covers the East Asia region: the full disk images are taken every $10 \mathrm{~min}$ with a $2 \mathrm{~km}$ spatial resolution. The analyses are conducted on the data of the hour over the domain of $120.132-134.243^{\circ} \mathrm{E}$ and $30.436-44.068^{\circ} \mathrm{N}$ $(600 \times 770$ grids), similar to the area of the precipitation data.

\section{Geostatistical methods}

In this study, we use several methods to analyze the spatial characteristics - the spatial autocorrelation, Moran's $I$, and general $G$. The spatial autocorrelation shows how the precipitation observations at a certain distance are correlated with each other. Thus, it is possible to determine the degree of spatial scale, or the effective influence range, of a single precipitation system or associated precipitation systems. Through Moran's $I$, we can figure out the property of spatial correlations, especially distinguishing between the cluster and dispersion type in the patterns and/or areas of precipitation. In other words, Moran's $I$ identifies local cluster areas of strong precipitation, large areas of precipitation, or precipitation boundaries. General $G$ indicates whether the cluster region has high or low precipitation.

\subsection{Spatial autocorrelation}

Autocorrelation in spatial analysis implies that a variable is correlated with itself at different points. Simply speaking, pairs of precipitation data close to each other are likely to have more similar values than those far apart from each other. When the precipitation data are spatially autocorrelated, precipitation at one place is related to that at another place, and they are not independent of each other. The autocorrelation coefficient can be obtained once the autocovariance has been calculated. The autocovariance indicates the degree of similarity of a variable itself at a certain distance. Generally, the autocovariance is greater as the separation distance decreases, becomes smaller as the distance increases, and does not show any tendency (e.g., converge) after a certain distance. For the one-dimensional data, the autocovariance (cov) in terms of the grid distance (or lag; $k$ ) between the data pairs, $X=\left(x_{1}, x_{2}, \cdots, x_{n-k}\right)$ and $X^{\prime}=\left(x_{1+k}\right.$, $\left.x_{2+k}, \cdots, x_{n}\right)$, is defined as

$$
\begin{aligned}
\operatorname{cov}\left(X, X^{\prime}\right) & =E\left[\left(X-\mu_{X}\right)\left(X^{\prime}-\mu_{X^{\prime}}\right)\right] \\
& =E\left(X X^{\prime}\right)-E(X) E\left(X^{\prime}\right) \\
& =\mu_{X X^{\prime}}-\mu_{X} \mu_{X^{\prime}} .
\end{aligned}
$$

Here, $E\left(X X^{\prime}\right), E(X)$, and $E\left(X^{\prime}\right)$ are the means of sub-data sets (i.e., $X X^{\prime}, X$, and $X^{\prime}$, respectively) and are calculated as follows:

$$
\begin{aligned}
& E\left(X X^{\prime}\right)=\frac{1}{n-k} \sum_{i=1}^{n-k} x_{i} x_{i+k}=\mu_{X X^{\prime}}, \\
& E(X)=\frac{1}{n-k} \sum_{i=1}^{n-k} x_{i}=\mu_{X}, \text { and } \\
& E\left(X^{\prime}\right)=\frac{1}{n-k} \sum_{i=1}^{n-k} x_{i+k}=\mu_{X^{\prime}},
\end{aligned}
$$

where $n$ is the number of total points and $i$ is the grid point index. The lag index, $k$, depicts the grid distance between two point values, $x_{i}$ and $x_{i+k}$. The autocorrelation coefficient $(\rho)$ is defined as

$\rho\left(X, X^{\prime}\right)=\frac{\operatorname{cov}\left(X, X^{\prime}\right)}{\sqrt{\operatorname{var}(X) \operatorname{var}\left(X^{\prime}\right)}}=\frac{\mu_{X X^{\prime}}-\mu_{X} \mu_{X^{\prime}}}{\sqrt{\operatorname{var}(X) \operatorname{var}\left(X^{\prime}\right)}}$,

where $\operatorname{var}(X)$ means the variance of $X$ and can be regarded as the covariance of $X$ with itself, i.e., $\operatorname{var}(X)=\operatorname{cov}(X, X)$. At the zero separation distance, the autocovariance has the same value as the variance and the autocorrelation coefficient becomes unity. For the two-dimensional data, the autocorrelation coefficient of all data pairs within the separation distance is obtained by using the relaxed separation distance and by following the same calculation principle as in the onedimensional data. In order to compute the relaxed separation distance, the distance between the data pairs is rounded.

\subsection{Moran's I}

Moran's $I$ is a statistical index for measuring the similarity of neighboring data (Moran, 1948). It is obtained by comparing the values of the target and neighboring feature pairs with the average of the entire targets:

$$
I=\frac{n \sum_{i} \sum_{i} j w_{i j}\left(x_{i}-\bar{x}\right)\left(x_{j}-\bar{x}\right)}{\sum_{i} \sum_{j} w_{i j} \sum_{i}\left(x_{i}-\bar{x}\right)^{2}},
$$

where $n$ is the number of the entire target observations, $x_{i}$ is the variable value at the $i$ th location and $\bar{x}$ is the mean of the entire targets. Here, $w_{i j}$ is the spatial weight of the link between $i$ and $j$, which is defined by the inverse distance 
weight, i.e., $w_{i j}=1 / d_{i j}$, with $d_{i j}$ representing the distance between grids $i$ and $j$. Moran's $I$ ranges from -1 to 1 with the following interpretation: (1) the positive value means that the variable of interest and its spatial lags are positively autocorrelated, defining a cluster pattern; (2) the negative value indicates spatially negative autocorrelation, defining a dispersion pattern; and (3) the zero value represents a random spatial pattern. Equation (4) denotes the global Moran's $I$ that identifies the pattern - either cluster or dispersion - but with no information on the magnitude of variables. In addition, the local Moran's $I\left(I_{i}\right)$, showing the location of the cluster and dispersion, is computed as the following (Anselin, 1995):

$I_{i}=\frac{\left(x_{i}-\bar{x}\right)}{\sum_{k=1}^{n}\left(x_{k}-\bar{x}\right)^{2} /(n-1)} \sum_{j=1}^{n} w_{i j}\left(x_{j}-\bar{x}\right)$.

$I_{i}$ is interpreted the same as $I$ but with no specific range. The $Z$ score $(Z)$ can be analyzed together to confirm the significance of $I_{i}$ and is calculated as

$Z\left(I_{i}\right)=\frac{I_{i}-E\left(I_{i}\right)}{\operatorname{SD}\left(I_{i}\right)}$,

where $E\left(I_{i}\right)=-\sum_{j} w_{i j} /(n-1)$ is the expected value of $I_{i}$ if random and $\operatorname{SD}\left(I_{i}\right)$ is the standard deviation of $I_{i}$. The $Z$ score suggests whether we can reject the null hypothesis or not. In this case, the null hypothesis states "there is no spatial clustering". To determine if the $Z$ score is statistically significant, we compare it to the range of values for a particular confidence level. For example, at the significance level of $0.1,0.05,0.01$, the absolute value of the $Z$ score would have to be greater than $1.65,1.96,2.57$, respectively, to be statistically significant, and the clusters are not created by chance.

\subsection{General $G$}

We can identify the cluster patterns through Moran's $I$; however, it does not indicate whether the clustered variable values are low or high. In addition to Moran's $I$, it is necessary to determine whether the properties of the cluster are hot spots (i.e., high values) or cold spots (i.e., low values) by using the Getis-Ord general $G$ (Getis and Ord, 1992; hereafter referred to as general $G$ ). The global general $G$, like the global Moran's $I$, shows the cluster characteristics for the entire study area as a statistical index. Therefore, we use the local general $G$ which can represent locations where features with either high or low values are spatially clustered. The following equation calculates the local general $G\left(G_{i}(d)\right)$ :
$G_{i}(d)=\frac{\sum_{j} w_{i j}(d) x_{j}}{\sum_{j} x_{j}}, j \neq i$,

where $d$ is the distance between the target feature and the neighboring feature, and $w_{i j}$ is the same spatial weight (i.e., the inverse distance weight) used for calculating Moran's $I$ as in Eqs. (4) and (5). To be a statistically significant hot spot or cold spot, the $Z$ score of the general $G$ can be calculated. Ord and Getis (1995) redefined $G_{i}(d)$, which can be considered as the $Z$ score $\left(Z\left(G_{i}\right)\right)$, as

$Z\left(G_{i}\right)=\frac{G_{i}-E\left(G_{i}\right)}{\operatorname{SD}\left(G_{i}\right)}, j \neq i$,

where $E\left(G_{i}\right)=\sum_{j} w_{i j}(d) /(n-1)$ is the expected value if random and $\operatorname{SD}\left(G_{i}\right)$ is the standard deviation of $G_{i}$. High positive values indicate the possibility of a local cluster of high values, whereas negative values indicate a similar cluster of low values. An absolute value of the $Z$ score would have to be greater than $1.65,1.96,2.57$ to be statistically significant at a significance level of $0.1,0.05,0.01$, respectively.

\section{Results and discussions}

\subsection{Spatial autocorrelation}

\subsubsection{Precipitation}

The general characteristics of the spatial autocorrelation structure in precipitation for each type are shown in Fig. 2. We have calculated the correlation coefficients for all points in the range from 0 to $100 \mathrm{~km}$. In order to compare the characteristics between different precipitation types, we defined the $e$-folding value as the threshold. The $e$-folding distance means the separation distance when autocorrelation becomes $e^{-1}$ (i.e., 0.3674 ). In other words, it refers to the spatial scale of precipitation that autocorrelation decreases to $\rho=e^{-1}$ from the value at the zero separation distance (i.e., $\rho=1$ ). The $e$-folding value, under the assumption that atmospheric variables decrease exponentially with time and distance, has often been used to estimate both the temporal and spatial structure of precipitation (e.g., Skøien et al., 2003; Ha et al., 2007; Kursinski and Mullen, 2008; Zeweldi and Gebremichael, 2009; In et al., 2014). As classified in Table 1, the LPMP and HPMP cases (i.e., $\mathrm{C} 1$ is high, regardless of $\mathrm{C} 2$ ) show the $e$-folding distance at $\sim 35 \mathrm{~km}$. On the other hand, the HPFP cases (i.e., $\mathrm{C} 1$ is low) depict the $e$-folding distance at $\sim 15 \mathrm{~km}$.

This result can be expected from the classification of precipitation types: precipitation with smaller spatial scale brings about more rapid decrease in the spatial correlation, thus showing smaller correlation at the $e$-folding distance. Ha 


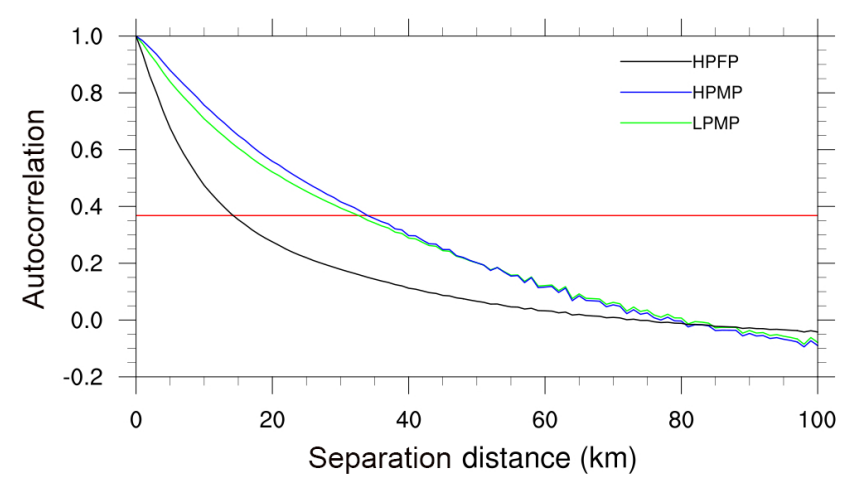

Figure 2. The averaged spatial autocorrelations of precipitation for each precipitation type. The red line indicates the $e$-folding value.

et al. (2007) estimated the $e$-folding distance of warm-season precipitation as $50-110 \mathrm{~km}$, and In et al. (2014) pointed out that the $e$-folding distance varied depending on months and regions with the minimum being $40 \mathrm{~km}$. Our results show shorter $e$-folding distances than those from the previous studies: it is ascribed to exclusion of the LPFP cases (see Table 1). Nam et al. (2014) examined the relationship between precipitation intensity and spatial autocorrelation and noticed that the latter became smaller as the former appeared stronger, thus depicting a larger locality in precipitation. They found that the $e$-folding distance was $14 \mathrm{~km}$ for the precipitation intensity in excess of $30 \mathrm{~mm} \mathrm{~h}^{-1}$, whereas it was about $40 \mathrm{~km}$ for the intensity greater than $5 \mathrm{~mm} \mathrm{~h}^{-1}$. However, our results indicate that the spatial autocorrelations of HPMP and LPMP are in similar shape. Generally, the spatial locality is proportional to precipitation intensity; however, strictly speaking, the number of points with precipitation has a greater effect on spatial characteristics than the precipitation intensity.

In Fig. 3, in order to identify the spatial characteristics of precipitation for each case, we show a histogram depicting the number of cases according to the $e$-folding distance. We found that the $e$-folding distance at the mode (the most frequent value) was $15 \mathrm{~km}$ for HPFP, $30 \mathrm{~km}$ for LPMP, and $\sim 34.7 \mathrm{~km}$ for HPMP, respectively. It is evident that, as shown in Fig. 2, the $e$-folding distance depends on the precipitation spatial scale rather than the precipitation intensity.

We additionally analyzed the directional features of precipitation distribution over the Korean Peninsula in order to know the spatial structures of precipitation systems (see Figs. 4 and 5). We classified the direction range from 0 to $180^{\circ}$ with an interval of $45^{\circ}$, considering the symmetry. Here, the direction is a measure of the angle from the origin-east axis, whose magnitude increases counterclockwise (see the radar chart in Fig. 5). Figure 4 shows the averaged directional autocorrelation for different precipitation types. The autocorrelation curves show similar shapes and properties in HPMP (Fig. 4a) and HPFP (Fig. 4c), which depict two distinct directional characteristics: the precipitation structures have similar spatial features in directional pairs of 45 and $0^{\circ}$
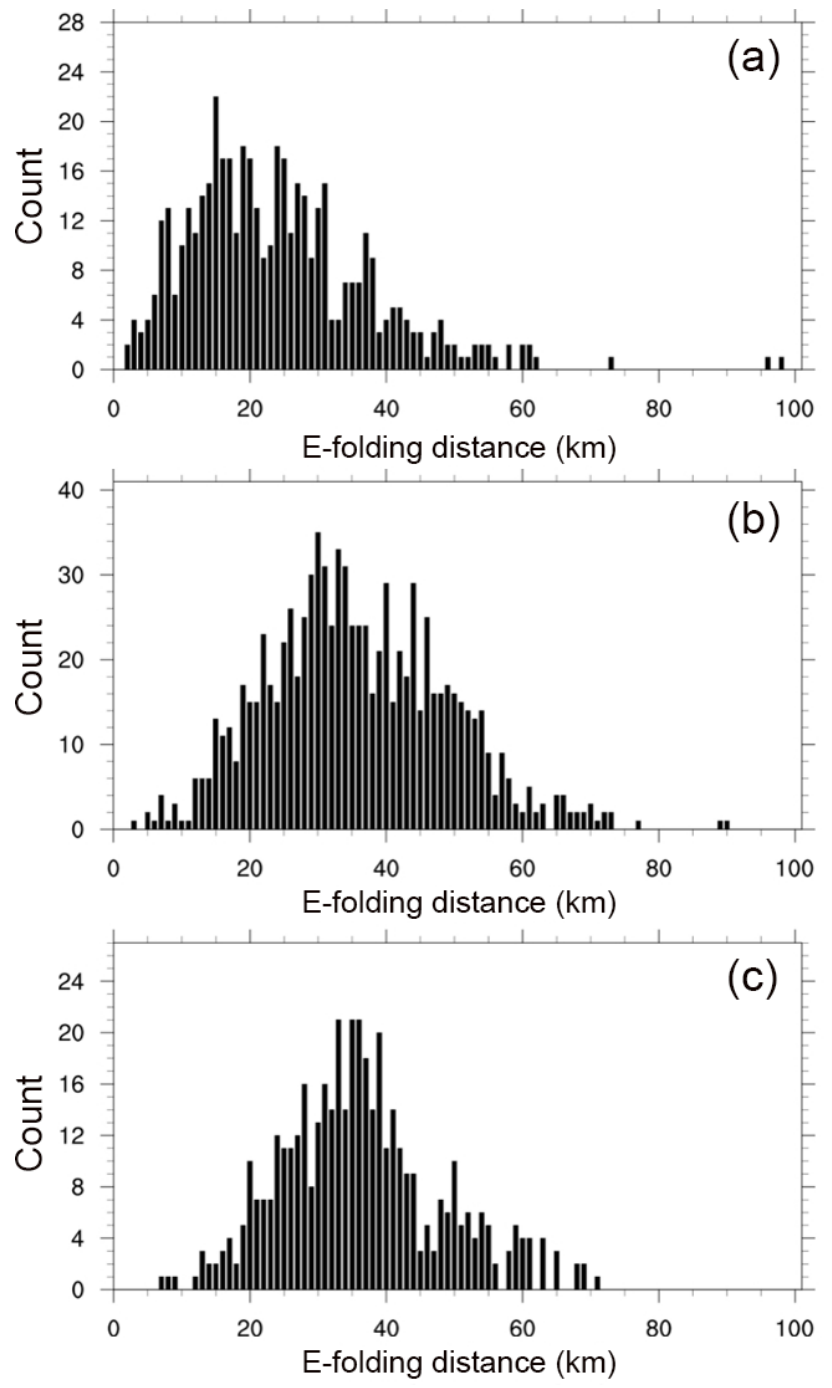

Figure 3. A histogram depicting the number of cases according to the $e$-folding distance for (a) HPFP, (b) LPMP, and (c) HPMP.

and of 135 and $90^{\circ}$. For HPFP where the precipitation spatial scale is small, the autocorrelations of all directions decrease more rapidly than those for LPMP and HPMP, resulting in a smaller gap between the two distinct curves compared to HPMP. For LPMP, i.e., low precipitation rate with a large spatial scale, the spatial correlation is highest with the precipitation axis of $45^{\circ}$ (i.e., southwest-northeast), whereas it is lowest with that of $135^{\circ}$ (northwest-southeast).

Figure 5 shows a radar chart representing the directional $e$-folding distance at the mode in the directional histogram of case numbers (not shown). In general, the directional $e$-folding distances (and hence the spatial correlations) are larger for the cases with large spatial scale (i.e., LPMP and HPMP) than the cases with small spatial scale (i.e., HPFP). It is noteworthy that the $e$-folding distances in LPMP have no characteristic directionality (i.e., isotropic), indicating that the precipitation systems in LPMP are mostly related to both 

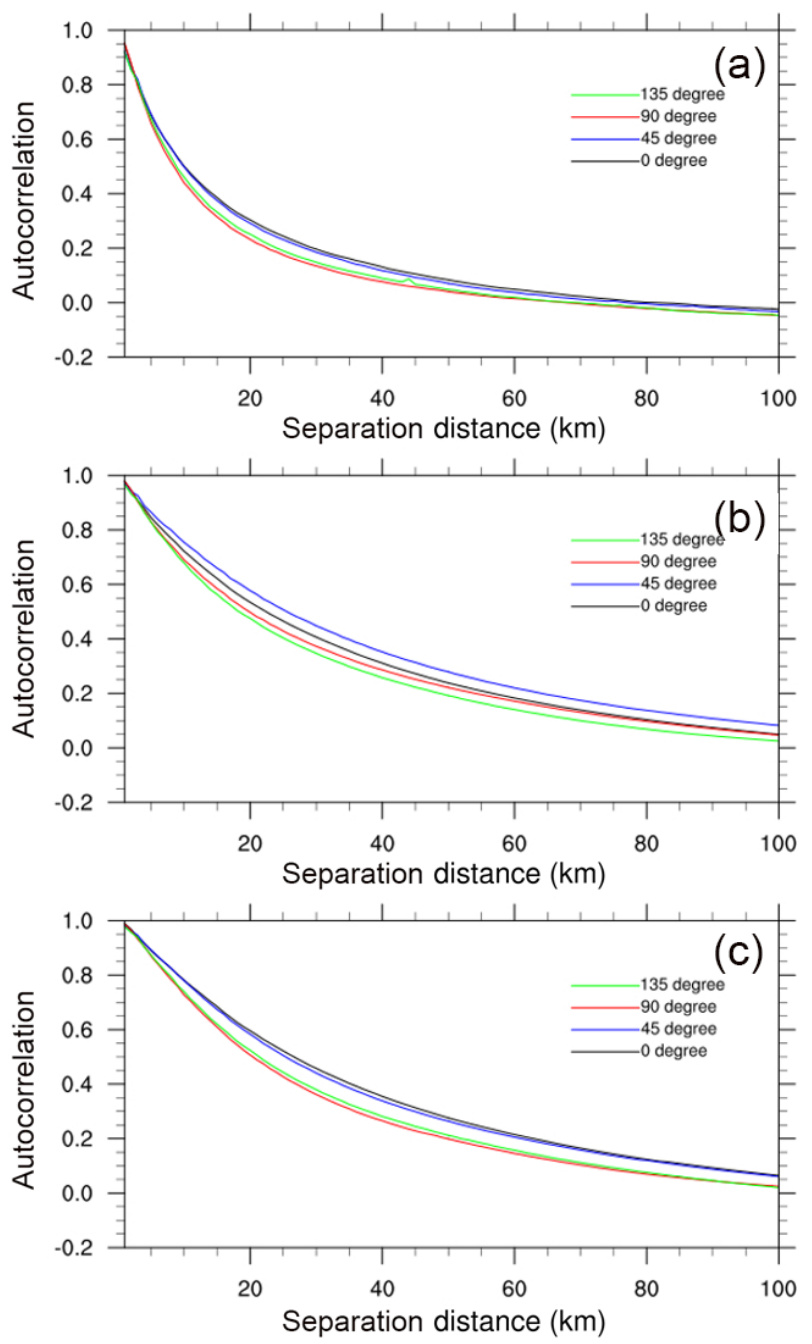

Figure 4. The averaged directional spatial autocorrelation of precipitation for (a) HPFP, (b) LPMP, and (c) HPMP.

the migratory cyclones that move into Korea from various directions and the cloud clusters where moderate convective systems in large area are closely connected to each other. On the other hand, the cases with high precipitation intensity, i.e., HPFP and HPMP, both show strong directionality (i.e., anisotropic) with large $e$-folding distances along the axes of 45 and $0^{\circ}$ (i.e., the southwest-northeast and west-east directions, respectively). They are considered to be strongly linked to the frontal rainfalls, convection bands, etc. (e.g., Sun and Lee, 2002; Kim and Lee, 2006; Lee et al., 2008; Jeong et al., 2012, 2016; Jung and Lee, 2013).

As we have used the 3-year data, the spatial autocorrelations here are considered to include the temporal features implicitly. All the weather systems evolve in time (i.e., develop, mature, and decay) and move in space during their life cycles. The fact that precipitation systems have a high correlation along a specific direction implies that those systems in

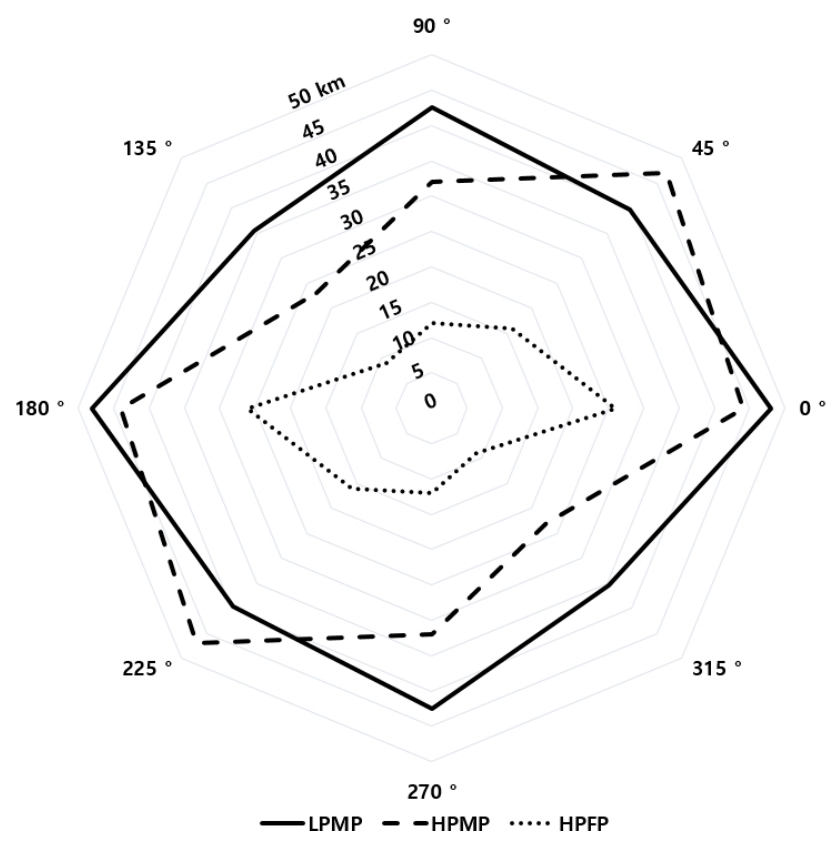

Figure 5. A radar chart representing the directional $e$-folding distance (in $\mathrm{km}$ ) for each precipitation type at the mode in the directional histogram (not shown) depicting the number of cases according to the $e$-folding distance in different directions.

that direction, even in the far distances, have similar/common structures or are originated from the same weather system. For instance, the meteorological systems with strong directionality include a squall line or a frontal system in which several thunderstorms banded together and a multicell cluster that comprises a series of individual storm at a different stage of life cycle with the same movement direction. For the multicell cluster, new cells form along the upwind edge of the cluster, and decaying cells are found along the downwind side with mature cells located at the center; thus, it includes evolutions in both space and time.

In terms of the summertime heavy precipitation systems over the Korean Peninsula, Lee and Kim (2007) classified them into four major types such as isolated thunderstorms, convection bands, squall lines and cloud clusters, whereas Song and Sohn (2015) classified them into two types: (i) the cold type characterized by an eastward-moving cloud system with an oval shape and (ii) the warm type with a comparatively wide spatial distribution over an area extending from the southwest to northeast. In our case, the precipitation events in HPFP may correspond to the isolated thunderstorms or the cold-type heavy rainfalls while those in HPMP correspond to convection bands, squall lines, cloud clusters, or the warm-type heavy rainfalls. On the other hand, Ha et al. (2007) investigated the monthly characteristics in the directional features of rainfall from May to September and reported that the cell type was dominant in May and September while the southwest-northeast tilted band type was ruling in 
Table 2. Monthly occurrences of precipitation systems according to the precipitation types from April to October in the period of 20132015.

\begin{tabular}{lrrr}
\hline & LPMP & HPMP & HPFP \\
\hline April & 277 & 31 & 21 \\
May & 106 & 54 & 37 \\
June & 130 & 50 & 186 \\
July & 191 & 213 & 250 \\
August & 193 & 158 & 326 \\
September & 138 & 56 & 116 \\
October & 122 & 32 & 44 \\
\hline
\end{tabular}

June-August. They addressed that the band type is mainly due to frontal rainfall during the rainy season. In our results, most cases of HPMP and HPFP occurred in July and August (see Table 2); thus, indicating that the warm-season precipitation systems in Ha et al. (2007) are mostly related to the long-lived (HPMP) and short-lived (HPFP) band-type heavy rainfalls along the monsoon frontal system.

\subsubsection{Himawari-8 water vapor bands}

Water vapor is the core element and driver of the precipitation development through dynamical processes (e.g., advection and convection) and physical processes (e.g., evaporation and condensation). For example, the East Asian monsoon starts when a huge amount of water vapor from the adjacent ocean is transported to the monsoon region by the large-scale atmospheric circulation. Thus, the spatial analysis of water vapor will contribute to further understanding of the spatial patterns of precipitation. Many studies have been carried out on the relationship between satellite water vapor and extratropical or tropical cyclones and storms (e.g., Velden, 1987; Milford and Dugdale, 1990; Krennert and Zwatz-Meise, 2003; De Haan et al., 2004; Rabin et al., 2004; Mukhopadhyay et al., 2005; Chosh et al., 2008).

By analyzing the water vapor imagery, we can detect not only the horizontal distribution of tropospheric water vapor but also the dynamical behavior of atmospheric flow such as the middle and upper troughs, vortexes, and jet streams, even in the absence of clouds. Therefore, analyzing the spatial characteristics of tropospheric water vapor is essential to improve the understanding of precipitation systems. In particular, we are focusing on the extent and direction of spatial correlation of water vapor flowing into the Korean Peninsula in association with the precipitation types.

In this study, we analyze the brightness temperatures from the Himawari- 8 water vapor bands to characterize the lower to upper atmosphere related to the precipitation systems. A humid atmosphere absorbs more longwave radiation from the Earth, resulting in a lower brightness temperature. On the other hand, a dry atmosphere absorbs less longwave radiation, bringing about a higher brightness temperature. Al- though we cannot directly quantify the amount of water vapor through the water vapor imager, we can sufficiently recognize the spatial distribution of water vapor. Moreover, using two water vapor bands (i.e., 6.2 and $7.3 \mu \mathrm{m}$ ), we can clearly identify the moisture boundaries at the zone between the warm/moist and cold/dry side of the jet/wind maximums at two different levels in the troposphere (Georgiev et al., 2016). The spatial analyses were performed with the mixed images of clouds and water vapor because it was hard to distinguish between clouds and water vapor without a cloud detection algorithm. Since both water vapor and clouds are strongly linked to precipitation as its sources, analysis of the mixed variables from the satellite data would not make a serious problem in understanding and relating to the precipitation systems. As we focus on the spatial distribution of water vapor when precipitation occurs, we analyze water vapor for each precipitation type.

The general characteristics of the spatial autocorrelation structure in water vapor bands for each precipitation type are shown in Fig. 6. The patterns of spatial autocorrelations of water vapor bands, for three precipitation types, are generally similar to those of precipitation; however, the separation distances extend much longer (cf. Fig. 2). Even at a separation distance of $100 \mathrm{~km}$, the spatial correlation is higher than 0.6. This strong spatial correlation is considered to be due to the continuity of water vapor. The largest spatial autocorrelation appears in LPMP, followed by HPMP and HPFP. The LPMP depicts similar correlation coefficients regardless of bands and hence heights of atmospheric layers. This implies that the spatial structure of water vapor bands is similar in the vertical. On the other hand, the spatial correlations in HPMP and HPFP become smaller along the downward path, from band 8 to band 10 .

In Fig. 7, the brightness temperature of water vapor bands characterizes directionality in the spatial correlations. In general, for all precipitation types and water vapor bands, the highest spatial correlations appear in the axis of $45^{\circ}$ (southwest-northeast) while the lowest in the axis of $135^{\circ}$ (northwest-southeast), as in precipitation (cf. Fig. 4). In LPMP, the spatial correlations in the axes of 0 and $90^{\circ}$ coincide even at longer distances. We also notice that, for a given precipitation type and separation distance, the spatial autocorrelation of water vapor becomes larger along the upward path, from band 10 to band 8 . Figure 8 shows the directional separation distances at the mode in the directional histogram of case numbers (not shown) for each precipitation type with the autocorrelation coefficients of 0.7 (blue), 0.8 (black), and 0.9 (grey), respectively. The separation distances generally show high values mainly in the axis of $45^{\circ}$, similar to the directional features of precipitation (cf. Fig. 5). Note that, in LPMP, the brightness temperature shows a large separation distance (i.e., high spatial correlation) in the axis of $45^{\circ}$ while precipitation depicts no directionality (cf. Fig. 5). This is possible because water vapor can form as a band type, e.g., over a stationary front, but precipitation can occur in cell type 

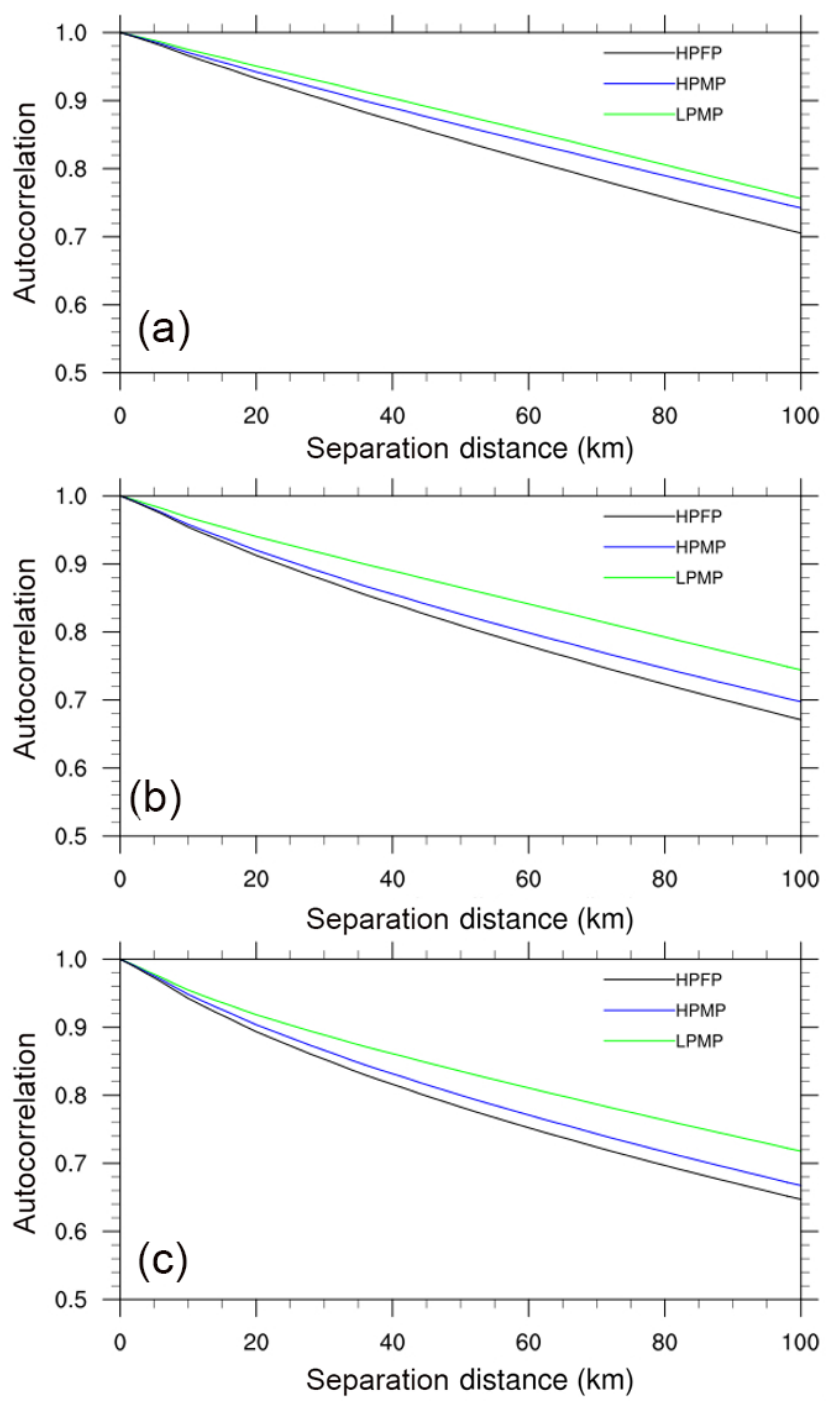

Figure 6. The averaged spatial autocorrelation of brightness temperature of the AHI water vapor band (a) 8, (b) 9, and (c) 10 for each precipitation type.

due to local features of convection over the same front. In addition, as the autocorrelation coefficient decreases, the directionality tends to disappear even though the autocorrelation coefficient is as large as 0.7. As in Fig. 7, we note that for a given precipitation type and spatial autocorrelation, the separation distance of water vapor becomes larger along the upward path. This is related to the stronger wind at upper atmosphere that carries the characteristic feature of water vapor further downstream.

Through the satellite water vapor analyses, we found both similarity and dissimilarity in spatial correlations between water vapor and precipitation. Similar to the results of precipitation analyses, the spatial autocorrelations of water vapor for HPFP decreased more rapidly than those for HPMP and LPMP (cf. Figs. 2 and 6). Water vapor and precipita- tion showed additional similarity in terms of characteristic directionality in spatial autocorrelations (cf. Figs. 4 and 7, and Figs. 5 and 8). However, both fields showed significant dissimilarity in the separation distances, i.e., the spatial scales (cf. Figs. 2 and 6). Note that water vapor makes phase changes and the conversion from water vapor to precipitation includes a bunch of nonlinear processes; thus, it is not surprising to see such dissimilarity. Further studies on the relationship between precipitation systems and satellite water vapor in Korea are essentially required.

\subsection{Moran's $I$ and general $G$}

Moran's I represents the spatial distribution pattern, i.e., cluster or dispersion: the cluster (dispersion) patterns appear in the areas with positive (negative) spatial autocorrelation. General $G$ determines whether the cluster area is a hot or cold spot: a hot (cold) spot means an area with high (low) values and hence high (low) precipitation amount. For all precipitation cases in this study, the values of the global Moran's $I$ showed positive values, meaning that clusters were detected, in the domain-average sense. Through the local Moran's $I\left(I_{i}\right)$, we can define the similarity between the target feature and its neighbors and check the spatial outliers as well (Lalor and Zhang, 2001; McGrath and Zhang, 2003). For example, with a negative $I_{i}$, the target feature may have high precipitation while its surroundings have low precipitation, and vice versa. Conversely, with a positive $I_{i}$, the target feature has a similar amount of precipitation as its neighbors. Thus, the local Moran's $I$ can detect strong precipitation over local clusters, precipitation boundaries, or precipitation over large areas. As Moran's I cannot distinguish between low and high precipitation, we employed the local general $G$ to identify the hot/cold spots (i.e., high/low precipitation areas, respectively). In order to calculate the indices, we selected a sub-domain for each precipitation case where the precipitation values were extracted at an interval of $5 \mathrm{~km}$. An inverse distance weighting function is used as the spatial weight.

We present the analysis results for three cases - one from each precipitation type (see Figs. 9-11). For the selected cases, the values of the global Moran's $I$ were all positive: 0.1207, 0.1711, and 0.2357 for the cases of LPMP, HPMP, and HPFP, respectively, with a higher value representing a stronger clustering. This indicates that all three cases show the cluster patterns. Figure 9 shows an LPMP case, which occurred at 05:00 KST (Korean Standard Time) on $25 \mathrm{Au}-$ gust 2015, in association with a tropical cyclone. Typhoon Goni (2015) approached from Japan and brought rainfall all over Korea (Fig. 9a). In particular, heavy precipitation systems, with more than $30 \mathrm{~mm} \mathrm{~h}^{-1}$, developed around the mountain range along the east-central coast of the Korean Peninsula. In Fig. 9b, the southeastern region is identified as hot spots (areas of high precipitation) while the southwestern region, over both land and sea, as cold spots (areas of low precipitation). Figure $9 \mathrm{c}$ depicts several precipitation 

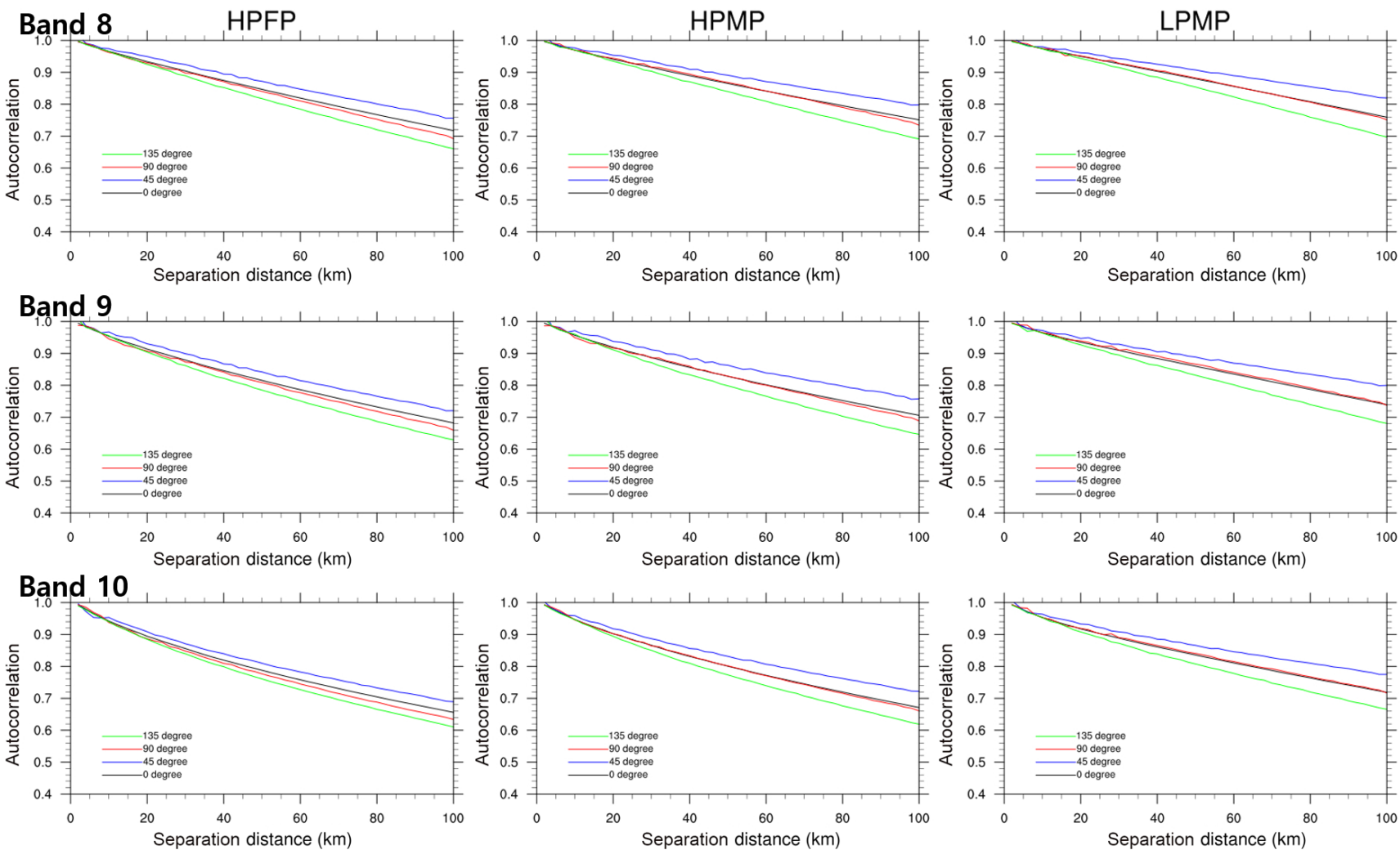

Figure 7. The averaged directional spatial autocorrelation of the brightness temperature of the AHI water vapor band 8 , 9 , and 10 by each precipitation type (i.e., HPFP, HPMP, and LPMP) for directions of $0^{\circ}$ (black), $45^{\circ}$ (blue), $90^{\circ}$ (red), and $135^{\circ}$ (green). The direction (angle) is measured counterclockwise from the origin-east axis (i.e., $0^{\circ}$ ).
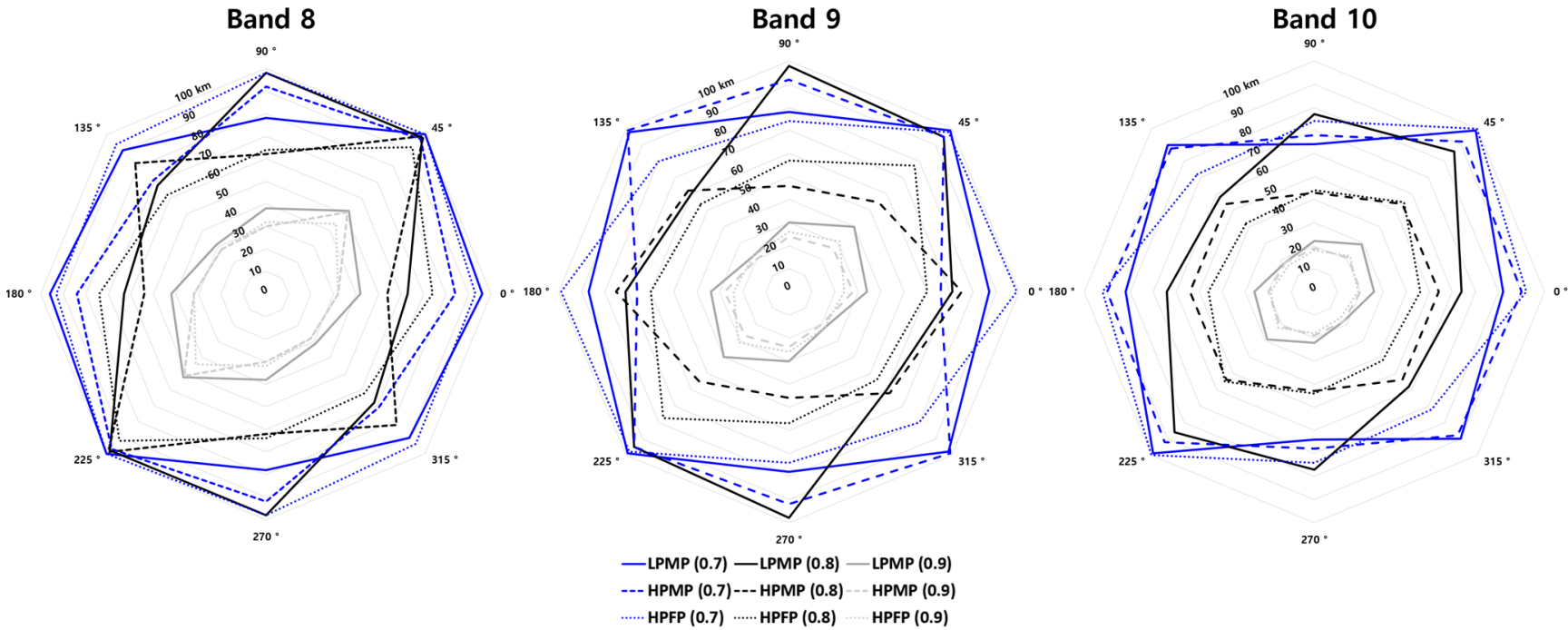

Figure 8. A radar chart representing the directional separation distance (in km) of brightness temperature of the AHI water vapor band 8, 9 , and 10 at the mode in the histogram of case numbers for LPMP (solid), HPMP (dashed), and HPFP (dotted). The colors indicate autocorrelation coefficients of 0.7 (blue), 0.8 (black), and 0.9 (grey), respectively. 

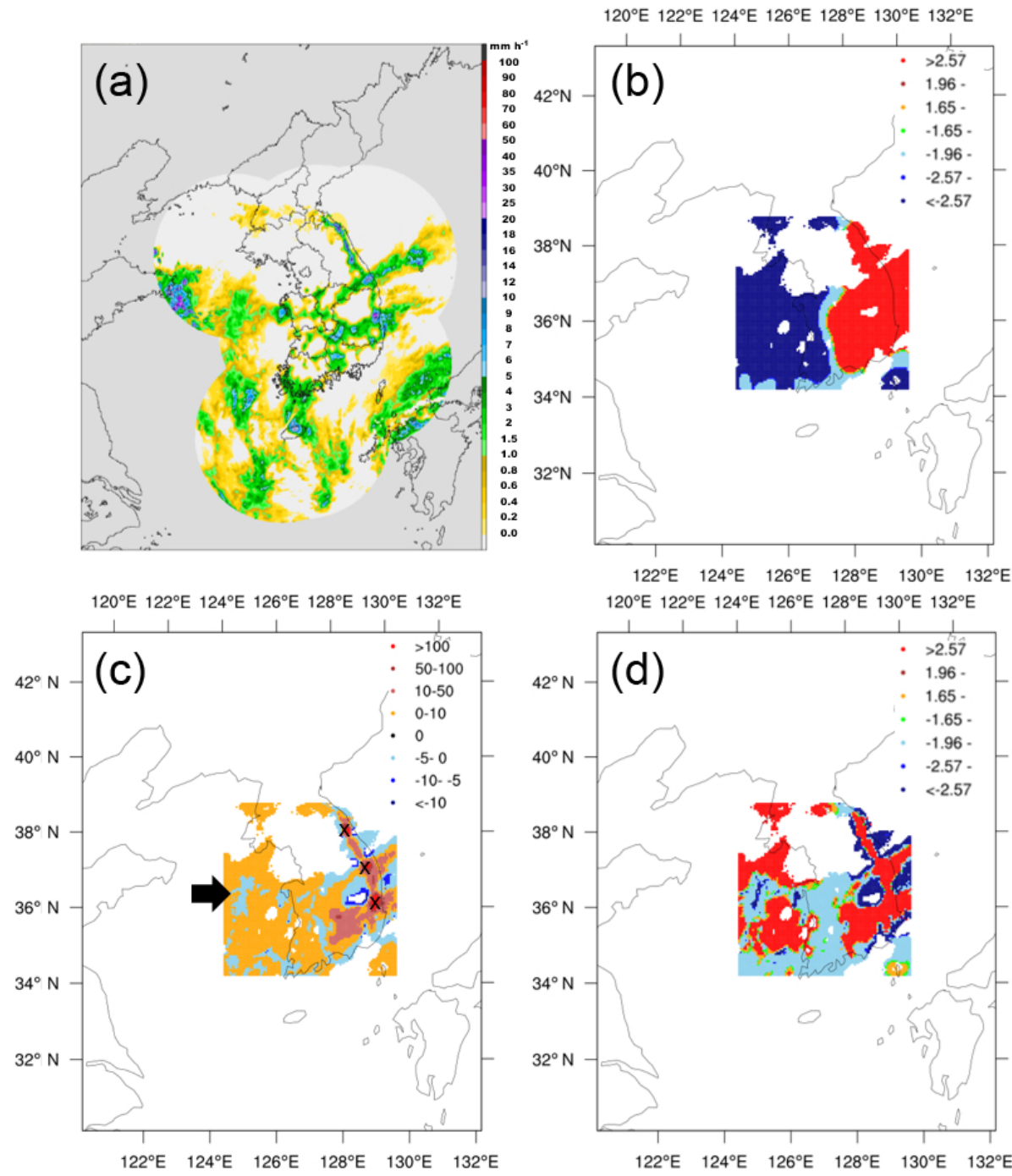

Figure 9. An LPMP case at 05:00 KST on 25 August 2015: (a) precipitation distribution (from https://afso.kma.go.kr/, last access: 10 February 2018), (b) local $Z\left(G_{i}\right)$, (c) local Moran's $I\left(I_{i}\right)$, and (d) $Z$ score of $I_{i}$. The computational domain covers the area of $34.34-38.97^{\circ} \mathrm{N}$ and $124.25-130.05^{\circ}$ E. Precipitation systems with maximum intensity and strong cluster characteristics are marked by the $X$ symbols, and the cold spots with dispersion pattern are denoted by the arrow. Non-precipitating areas have no color shading.

systems with maximum intensity (i.e., precipitation rate; see Fig. 9a) in the cluster area (marked by the $\mathrm{X}$ symbols). These systems show the highest local Moran's $I$ with the spatial scale of less than $30 \mathrm{~km}$. The cluster patterns were statistically significant at a significance level of 0.01 (Fig. 9d). In Fig. 10, we illustrate a heavy rainfall case in the category of HPMP, which occurred at 17:00 KST on 27 May 2013 as a migratory cyclone approached from the west, passed over the Korean Peninsula slowly, and brought rainfall throughout the country, mainly in the western and southern regions (Fig. 10a). Such precipitation areas matched well with the hot spots in Fig. 10b. The map of local Moran's I shows that a precipitation system with a strong cluster feature has developed, over the southwestern sea of the Korean Peninsula, along with the successive cluster patterns in a line type
(Fig. 10c), with a significance level of 0.01 (Fig. 10d). Figure 11 shows an HPFP case, which occurred at 05:00 KST on 24 October 2015. The central-western region of the Korean Peninsula received rainfall of more than $8 \mathrm{~mm} \mathrm{~h}^{-1}$ (Fig. 11a): the hot spots appeared in the precipitation area while the cold spots were located at the region of relatively low precipitation (Fig. 11b). Figure 11c illustrates an intense cluster pattern (dark red) over the relatively high rainfall area and a weaker cluster pattern over the cold spot, with a significance level of about 0.01 (Fig. 11d).

Overall, the spatial structures of the selected precipitation systems are well presented by the analyses of Moran's $I$ and general $G$. The overall spatial pattern (cluster vs. dispersion) of a precipitation system is characterized by the global Moran's $I$, whereas the spatial distributions of clus- 

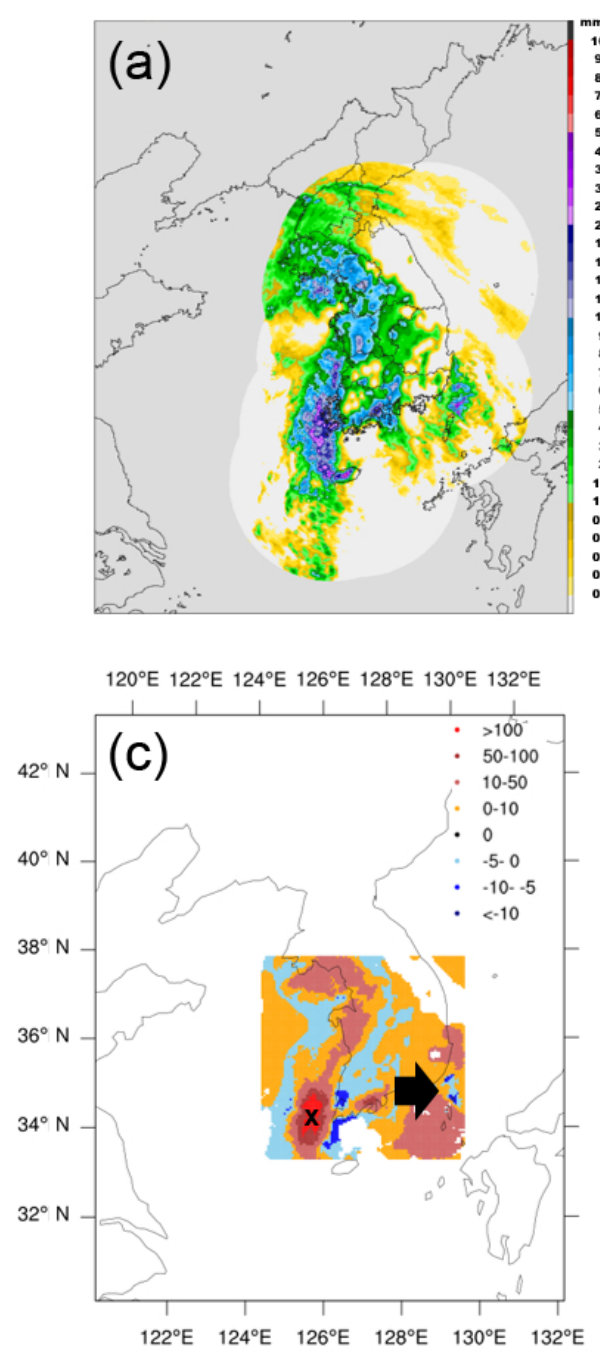

$120^{\circ} \mathrm{E} 122^{\circ} \mathrm{E} 124^{\circ} \mathrm{E} 126^{\circ} \mathrm{E} 128^{\circ} \mathrm{E} 130^{\circ} \mathrm{E} 132^{\circ} \mathrm{E}$
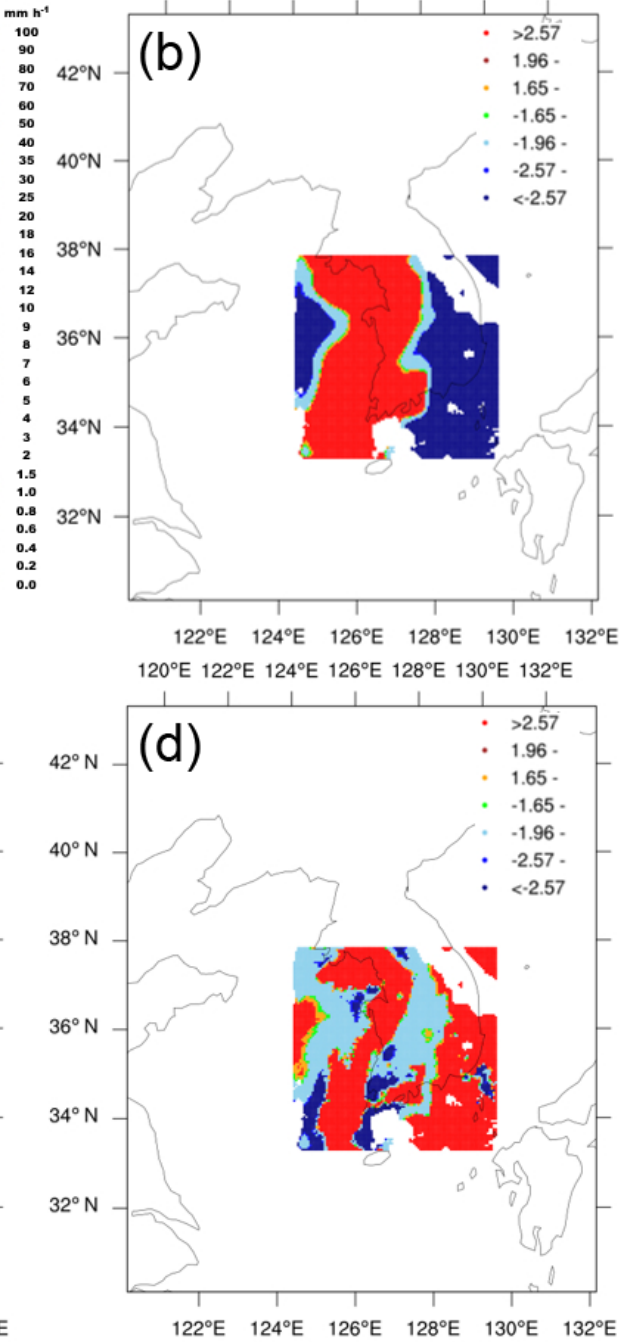

Figure 10. Same as in Fig. 9 but for an HPMP case at 17:00 KST on 27 May 2013 and the computational domain of 33.43-38.05 ${ }^{\circ}$ and $124.25-130.04^{\circ} \mathrm{E}$.

tered areas are represented by the local Moran's $I$. The overall regional features of precipitation amount (i.e., hot vs. cold spot) are captured by the local general $G$. For example, precipitation in the HPFP case, relevant to convective clusters, appeared over a small local area (Fig. 11a) but the value of the global Moran's $I$ was much higher (0.2357) than the others (0.1207 and 0.1711), implying a stronger cluster pattern; however, considering that the global Moran's $I$ is a domainaveraged value, this high value may be due to fewer dispersion (negative correlation) areas. In fact, the HPFP case shows a relatively weaker dispersion area (Fig. 11c), compared to the LPMP and HPMP cases (Figs. 9c and 10c, respectively). It is notable that the cluster pattern shows different spatial characteristics depending on the spatial scale and distribution feature of precipitation systems: several strong local clusters develop, especially over areas of high precipitation, when precipitation occurs over a large region (Figs. 9 and 10), whereas weaker clusters develop when precipitation occurs over a small region (Fig. 11). Through the integrated interpretation of these indices, we discovered some important spatial features of the precipitation systems: (1) the area where the cluster pattern overlaps with the hot spots is characterized by heavy rainfall (e.g., the X-marked or dark red places in Figs. 9c and 10c); (2) the area where the dispersion pattern concurs with the cold spots is distinguished by a relatively high precipitation surrounded by low precipitation (e.g., the rain cells denoted by arrows in Figs. 9c and 10c); (3) the precipitation gets weaker as it moves away from the strong cluster area - that is, the cluster pattern appears at the center and the dispersion pattern appears around; and (4) the secondary cluster pattern in a precipitation system over a wide area indicates clusters of low-intensity precipitation. 


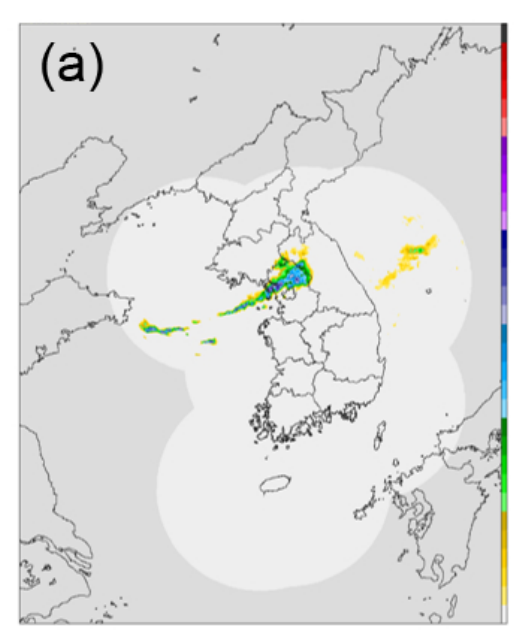

$120^{\circ} \mathrm{E} 122^{\circ} \mathrm{E} 124^{\circ} \mathrm{E} 126^{\circ} \mathrm{E} 128^{\circ} \mathrm{E} 130^{\circ} \mathrm{E} 132^{\circ} \mathrm{E}$

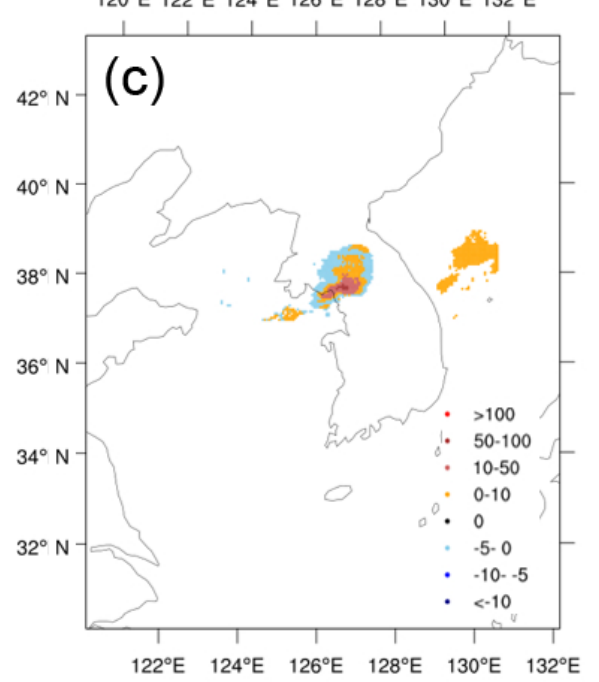

$120^{\circ} \mathrm{E} 122^{\circ} \mathrm{E} 124^{\circ} \mathrm{E} 126^{\circ} \mathrm{E} 128^{\circ} \mathrm{E} 130^{\circ} \mathrm{E} 132^{\circ} \mathrm{E}$

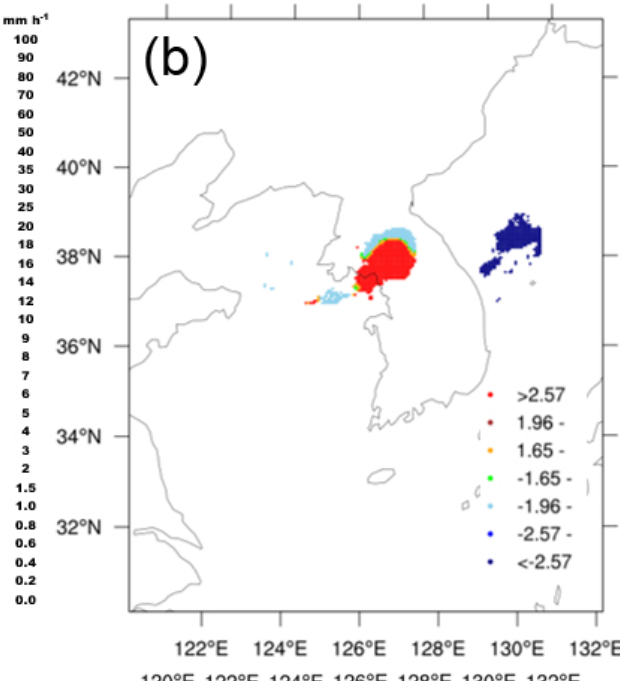

$120^{\circ} \mathrm{E} 122^{\circ} \mathrm{E} 124^{\circ} \mathrm{E} 126^{\circ} \mathrm{E} 128^{\circ} \mathrm{E} 130^{\circ} \mathrm{E} 132^{\circ} \mathrm{E}$

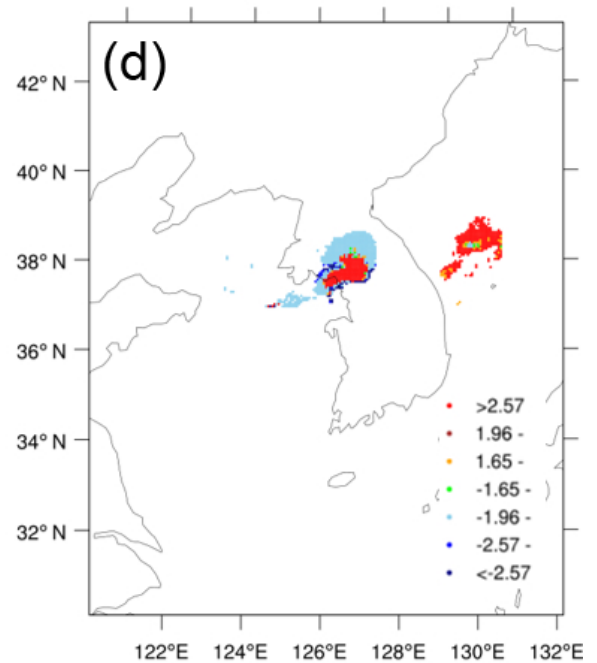

Figure 11. Same as in Fig. 9 but for an HPFP case at 05:00 KST on 24 October 2015 and the computational domain of $37.14-39.06^{\circ} \mathrm{N}$ and $123.32-131.21^{\circ} \mathrm{E}$.

\subsection{Temporal autocorrelation}

We additionally calculated the temporal autocorrelation coefficients of precipitation and water vapor bands for each precipitation type. For precipitation, HPFP represents the shortest $e$-folding time, followed by LPMP and HPMP (Fig. 12). This order in the $e$-folding time is the same as in the $e$-folding distance: this implies that, for the precipitation types classified here, the temporal correlation as well as the spatial correlation appears greater in the precipitation systems over a larger area than that over a smaller area. The range of the $e$-folding time for all precipitation types is $1-2 \mathrm{~h}$. The averaged temporal autocorrelations of water vapor bands show similar features to those of precipitation for different precipitation types, though the correlations decrease slowly over time (Fig. 13). In addition, compared with the spatial cor- relations, the temporal correlations do not show significant dependence on the height of atmospheric layer.

Through this temporal correlation analyses, we noticed that the $e$-folding time is in a short range (1-2h), and its difference among different precipitation types is only about $30 \mathrm{~min}$. This short $e$-folding timescale for all precipitation types implies that the precipitation systems affecting Korea in the warm season are mostly characterized by convectivetype precipitation, from either isolated storm cells or clustered bands, at least for the given analysis period. The $e$ folding timescale suggests an adequate time interval for data collection and analysis for capturing the detailed structure of and better forecasting of precipitation systems. It also implies a proper time interval for incorporating observations in the operational data assimilation system, for more accurate numerical forecasting of the precipitation systems. 


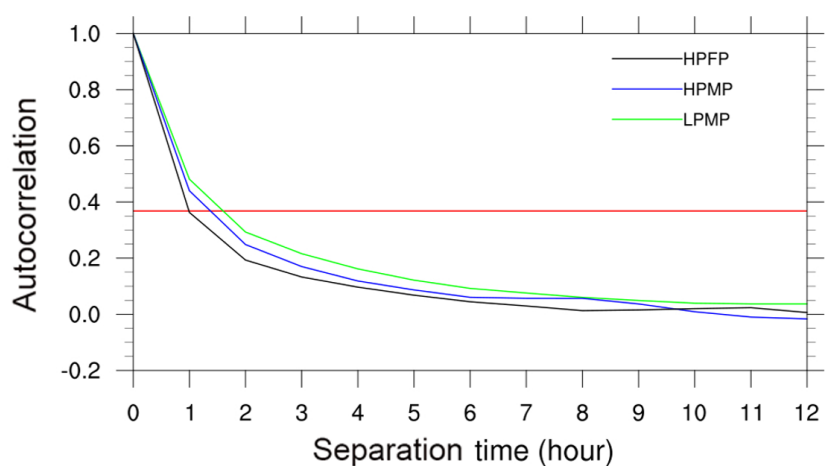

Figure 12. Same as in Fig. 2 but for the averaged temporal autocorrelation.

Moreover, Ha et al. (2007) reported that the $e$-folding time of precipitation in Korea is $1-2 \mathrm{~h}$ regardless of months (from May to September) and that the monthly difference of the $e$ folding time is approximately $30-40 \mathrm{~min}$. Therefore, we can conclude that the typical $e$-folding time of the warm-season precipitation systems in Korea is $1-2 \mathrm{~h}$, regardless of the precipitation types and months. This conclusion is based on the analyses of the hourly precipitation data: we may find different temporal characteristics for different precipitation types using a data set of shorter interval (e.g., $10 \mathrm{~min}$ ). In terms of the satellite water vapor data, a further study is also necessary to investigate the relationship between water vapor transport and precipitation, regarding the temporal scale as well as the spatial scale, with more detailed analyses.

\section{Conclusions}

Heavy rainfall causes many casualties as well as property damage, and thus its accurate forecast is very important. To improve the forecast accuracy, it is necessary to understand the characteristics of the precipitation systems through analyses of data from observation and/or numerical modeling. Furthermore, a well-designed observation network is essentially required to capture the characteristic features of precipitation systems.

In this study, we identify the characteristics of warmseason precipitation systems in Korea, via the geostatistical analyses on the composite precipitation and satellite water vapor data. We have classified the precipitation cases into four types, based on the average rainfall amount per point and the ratio of the points with precipitation (i.e., spatial scale): (1) low precipitation at a few points (LPFP); (2) low precipitation at many points (LPMP); (3) high precipitation at a few points (HPFP); and (4) high precipitation at many points (HPMP), among which the LPFP cases are excluded from the analysis.

We have conducted analyses of the spatial and temporal autocorrelations of precipitation and water vapor for the precipitation cases of each classification type and found that the
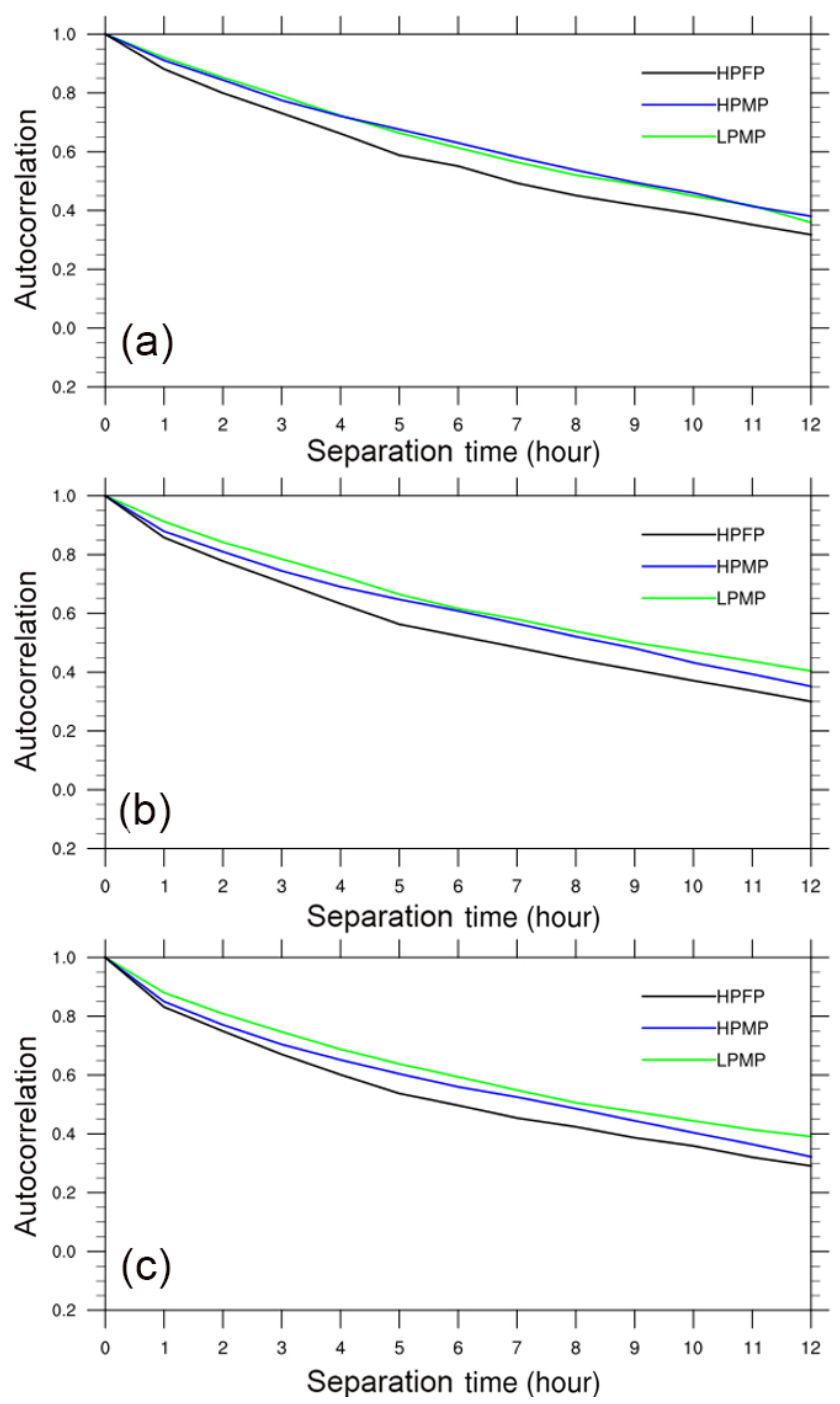

Figure 13. Same as in Fig. 6 but for the averaged temporal autocorrelation.

$e$-folding distance of precipitation ranges between 15 and $35 \mathrm{~km}$ while the $e$-folding time ranges between 1 and $2 \mathrm{~h}$. The $e$-folding distance is as short as $15 \mathrm{~km}$ for an HPFP case (e.g., a local shower), but as large as $\sim 35 \mathrm{~km}$ for the cases of both LPMP and HPMP, implying that the spatial correlation becomes larger as precipitation occurs over a wider area and is less affected by the precipitation amount. We also noted that the spatial autocorrelations have the following characteristic directionality: (1) precipitation systems with high precipitation amount (i.e., HPFP and HPMP) have high spatial autocorrelations in the southwest-northeast and west-east directions, mainly associated with frontal rainfalls during the monsoon season; and (2) those with low precipitation amount (i.e., LPMP) have no directionality, pertaining to both the migratory cyclones moving in various directions and the moderate convective systems in the cloud clusters. Other spatial characteristics were identified as well, including cluster ver- 
sus dispersion patterns, hot versus cold spots, strong precipitation over local clusters, precipitation boundaries, precipitation over a large area, and so forth. In general, heavy rainfalls appear over the hot spots with the cluster pattern while an isolated high-precipitation system, surrounded by low precipitation, occurs over the cold spots with the dispersion pattern.

The Advanced Himawari Imager, onboard Himawari-8, has three water vapor bands $-8(6.2 \mu \mathrm{m}), 9(6.9 \mu \mathrm{m})$, and $10(7.3 \mu \mathrm{m})$ - representing the lower atmospheric layer with higher wavelength. Since water vapor has continuity in time and space, the autocorrelation coefficients of water vapor bands drop more slowly than those of the composite precipitation. However, the comparative analyses according to the precipitation type reveal that the spatial correlations of water vapor bands behave similarly to those of precipitation: the correlations of water vapor bands are also large (small) for precipitation systems which occurred over a large (small) area.

We can also assess the current observational network in Korea, focusing on the warm-season precipitation systems, via the geostatistical analyses. Currently, the precipitation observation network in Korea has a spatial resolution of $\sim 13 \mathrm{~km}$, distributing the analysis over an interval of $1 \mathrm{~h}$. For a standard based on the $e$-folding values, such observation network is capable of deriving the spatiotemporal characteristics of the precipitation systems in all three types LPMP, HPMP, and HPFP. However, if we apply a strict standard (e.g., autocorrelation of 0.6), the separation distance and time for the HPFP cases fall down to $\sim 6 \mathrm{~km}$ and $\sim 35 \mathrm{~min}$, respectively. This implies that, regarding the spatial resolution, the current observation network can hardly capture the characteristic features of the localized precipitation systems; the temporal resolution might be sufficiently high because the composite precipitation data are produced every $10 \mathrm{~min}$. Therefore, for more accurate analyses of the precipitation systems with a higher correlation, a denser observation network should be considered in local areas where a heavy rainfall often occurs. This study has enabled us not only to explore the characteristics of precipitation systems in Korea but also to suggest the criteria for evaluating the observation network.

We note that the spatial distribution and movement features of the precipitation systems are strongly affected by terrain, but the orographic effect is not fully assessed in this study. Bacchi and Kottegoda (1995) demonstrated the orographic effect of the Alps mountain range on the spatial distribution of the rainfalls and addressed the directional characteristics of the spatial correlations. Other studies also confirmed the direct and induced effect of mountains on the spatial distribution of rainfall (e.g., Mass, 1981; Carruthers and Choularton, 1983; Barros and Kuligowski, 1997; Park and Lee, 2007). As the Korean Peninsula is represented by a highly complex terrain with many mountains, the spatial properties of precipitation systems will be distinctively affected. It is essential to conduct further research about the orographic effect on the spatiotemporal characteristics of precipitation, specifically over different slope sides of various mountain ranges in Korea. We additionally suggest a further study to analyze the autocorrelations by considering the storm cell movement and the occurrences of initial precipitation and maximum rainfall intensity.

Data availability. The composite precipitation and Himawari8 data are available from the Korea Meteorological Administration database: http://203.247.66.28/ (Hwang et al., 2015; Bessho et al., 2016) (instructed in Korean), in which a user registration is required. The Himawari-8 data is also disseminated via the HimawariCast from the Japan Meteorological Agency at http://www.data.jma.go.jp/mscweb/en/himawari89/ himawari_cast/himawari_cast.html (Bessho et al., 2016).

Competing interests. The authors declare that they have no conflict of interest.

Acknowledgements. This work is supported by the Korea Meteorological Administration (KMA) Research and Development Program under Grant KMIPA, mainly through KMIPA2016-1010 and partly through KMI2018-06710. We acknowledge KMA for supplying the composite precipitation and the Himawari-8 water vapor bands data.

Edited by: Luis Samaniego

Reviewed by: Xing Yu and two anonymous referees

\section{References}

Anselin, L.: Local Indicators of Spatial Association - LISA, Geogr. Anal., 27, 93-115, https://doi.org/10.1111/j.15384632.1995.tb00338.x, 1995.

Bacchi, B. and Kottegoda, N. T.: Identification and calibration of spatial correlation patterns of rainfall, J. Hydrol., 165, 311-348, 1995.

Barros, A. P. and Kuligowski, R. J.: Orographic effects during a severe wintertime rainstorm in the Appalachian mountain, Mon. Weather Rev., 126, 2648-2672, 1997.

Barton, Y., Giannakaki, P., Von Waldow, H., Chevalier, C., Pfahl, S., and Martius, O.: Clustering of regional-scale extreme precipitation events in southern Switzerland, Mon. Weather Rev., 144, 347-369, 2016.

Bessho, K., Date, K., Hayashi, M., Ikeda, A., Imai, T., Inoue, H., Kumagai, Y., Miyakawa, T., Murata, H., Ohno, T., Okuyama, A., Oyama, R., Sasaki, Y., Shimazu, Y., Shimoji, K., Sumida, Y., Suzuki, M., Taniguchi, H., Tsuchiyama, H., Uesawa, D., Yokota, H., and Yoshida, R.: An introduction to Himawari-8/9 - Japan's new-generation geostationary meteorological satellites, J. Meteorol. Soc. Jpn. Ser. II, 94, 151-183, https://doi.org/10.2151/jmsj.2016-009, 2016.

Bretherton, C. S., Peters, M. E., and Back, L. E.: Relationships between water vapor path and precipitation over the tropical 
oceans, J. Climate, 17, 1517-1528, https://doi.org/10.1175/15200442(2004)017<1517:RBWVPA>2.0.CO;2, 2004.

Carruthers, D. J. and Choularton, T. W.: A model of the feederseeder mechanism of orographic rain including stratification and wind-drift effects, Q. J. Roy. Meteorol. Soc., 109, 575-588, 1983.

Cassardo, C., Park, S. K., Thakuri, B. M., Priolo, D., and Zhang, Y.: Soil surface energy and water budgets during a monsoon season in Korea, J. Hydrometeorol., 10, 1379-1396, 2009.

Chang, H. and Kwon, W.-T.: Spatial variations of summer precipitation trends in South Korea, 1973-2005, Environ. Res. Lett., 2, 045012, https://doi.org/10.1088/1748-9326/2/4/045012, 2007.

Choi, S.-W., Lee, S.-J., Kim, J. Lee, B.-L., Kim, K.-R., and Choi, B.-C.: Agrometeorological observation environment and periodic report of Korea Meteorological Administration: Current status and suggestions, Korean J. Agr. Forest Meteorol., 17, 144155, https://doi.org/10.5532/KJAFM.2015.17.2.144, 2015.

Chosh, A., Lohar, D., and Das, J.: Initiation of Nor'wester in relation to mid-upper and low-level water vapor patterns on METEOSAT-5 images, Atmos. Res., 87, 116-135, 2008.

Ciach, G. J. and Krajewski, W. F.: Analysis and modeling of spatial correlation structure in small-scale rainfall in Central Oklahoma, Adv. Water Resour., 29, 1450-1463, 2006.

De Haan, S., Barlag, S., Baltink, H. K., Debie, F., and Van der Marel, H.: Synergetic use of GPS water vapor and Meteosat images for synoptic weather forecasting, J. Appl. Meteorol., 43, 514-518, 2004.

Eltahir, E. A. B. and Bras, R. L.: Precipitation recycling, Rev. Geophys., 34, 367-378, https://doi.org/10.1029/96RG01927, 1996.

Emmanuel, I., Andrieu, H., Leblois, E., and Flahaut, B.: Temporal and spatial variability of rainfall at the urban hydrological scale, J. Hydrol., 430, 162-172, 2012.

Feng, Y. and Kitzmiller, D. H.: A short-range quantitative precipitation forecast algorithm using back-propagation neural network approach, Adv. Atmos. Sci., 23, 405-414, 2006.

Fritsch, J. M., Houze Jr., R. A., Adler, R., Bluestein, H., Bosart, L., Brown, J., Carr, F., Davis, C., Johnson, R. H., Junker, N., Kuo, Y.-H., Rutledge, S., Smith, J., Toth, Z., Wilson, J. W., Zipser, E., and Zrnic, D.: Quantitative precipitation forecasting: Report of the eighth prospectus development team, U.S. Weather Research Program, B. Am. Meteorol. Soc., 79, 285-299, 1998.

Fu, W. J., Jiang, P. K., Zhou, G. M., and Zhao, K. L.: Using Moran's $I$ and GIS to study the spatial pattern of forest litter carbon density in a subtropical region of southeastern China, Biogeosciences, 11, 2401-2409, https://doi.org/10.5194/bg-112401-2014, 2014.

Georgiev, C. G., Santurette, P., and Maynard K.: Weather Analysis and Forecasting: Applying Satellite Water Vapor Imagery and Potential Vorticity Analysis, 2nd Edn., Academic Press, Cambridge, USA, 2016.

Getis, A. and Ord, J. K.: The analysis of spatial association by use of distance statistics, Geogr. Anal., 24, 189-206, 1992.

Gimeno, L., Stohl, A., Trigo, R. M., Dominguez, F., Yoshimura, K., Yu, L., Drumond, A., Durán-Quesada, A. M., and Nieto, R.: Oceanic and terrestrial sources of continental precipitation, Rev. Geophys., 50, RG4003, https://doi.org/10.1029/2012RG000389, 2012.
Ha, K.-J., Jeon, E.-H., and Oh, H.-M.: Spatial and temporal characteristics of precipitation using an extensive network of ground gauge in the Korean Peninsula, Atmos. Res., 86, 330-339, 2007.

Hong, K.-O., Shu, M.-S., and Rha, D.-K.: Temporal and spatial variations of precipitation in South Korea for recent 30 Years (19762005) and geographic environments, J. Korean Earth Sci. Soc., 27, 433-449, 2006.

Hwang, D.-I., Lee, J. W., Seo, D.-I., Na, H., and Seo, Y.-K.: Prediction system using extrapolation-based nowcasting techniques for very short-range forecasting and improvement of $1 \mathrm{hr}$ accumulated precipitation forecasts, in: Proceedings of the Autumn Meeting of Korean Meteorological Society, 12-14 October 2015, Jeju, Korea, 260-261, http://203.247.66.28/, 2015.

In, S.-R., Han, S.-O., Im, E.-S., Kim, K.-H., and Shim, J.: Study on temporal and spatial characteristics of summertime precipitation over Korean Peninsula, Atmos., 24, 159-171, 2014 (in Korean with English abstract).

Jeong, J.-H., Lee, D.-I., Wang, C.-C., Jang, S.-M., You, C.-H., and Jang, M.: Environment and morphology of mesoscale convective systems associated with the Changma front during 9-10 July 2007, Ann. Geophys., 30, 1235-1248, https://doi.org/10.5194/angeo-30-1235-2012, 2012.

Jeong, J.-H., Lee, D.-I., Wang, C.-C., and Han, I.-S.: Characteristics of mesoscale-convective-system-produced extreme rainfall over southeastern South Korea: 7 July 2009, Nat. Hazards Earth Syst. Sci., 16, 927-939, https://doi.org/10.5194/nhess-16-9272016, 2016.

Jung, W. and Lee, T.-Y.: Formation and evolution of mesoscale convective systems that brought the heavy rainfall over Seoul on September 21, 2010, Asia-Pacific J. Atmos. Sci., 49, 635-647, https://doi.org/10.1007/s13143-013-0056-4, 2013.

Kim, B. J., Kripalani, R., Oh, J. H., and Moon, S.-E.: Summer monsoon rainfall patterns over South Korea and associated circulation features, Theor. Appl. Climatol. 72, 65-74, https://doi.org/10.1007/s007040200013, 2002.

Kim, E.-H., Kim, M.-K., and Lee, W.-S.: The regional characteristics of daily precipitation intensity in Korea for recent 30 years, J. Korean Earth Sci. Soc., 26, 404-416, 2005.

Kim, H. W. and Lee, D. K.: An observational study of mesoscale convective systems with heavy rainfall over the Korean Peninsula, Weather Forecast., 21, 125-148, https://doi.org/10.1175/WAF912.1, 2006.

Kim, O. Y. and Oh, J. H.: Verification of the Performance of the High Resolution QPF Model for Heavy Rainfall Event over the Korean Peninsula, Asia-Pacific J. Atmos. Sci., 46, 119-133, 2010.

Ko, J.-W., Baek, H.-J., and Kwon, W.-T.: The characteristics of precipitation and regionalization during rainy season in Korea, J. Korean Meteorol. Soc., 41, 101-114, 2005.

Krennert, T. and Zwatz-Meise, V.: Initiation of convective cells in relation to water vapour boundaries in satellite images, Atmos. Res., 67-68, 353-366, 2003.

Kursinski, A. L. and Mullen, S. L.: Spatiotemporal variability of hourly precipitation over the eastern contiguous United States from stage IV multisensor analyses, J. Hydrometeorol., 9, 3-21, 2008.

Lalor, G. and Zhang, C. S.: Multivariate outlier detection and remediation in geochemical databases, Sci. Total Environ., 281, 99109, 2001. 
Lee, D.-K., Park, J.-G., and Kim, J.-W.: Heavy Rainfall Events Lasting 18 Days from July 31 to August 17, 1998, over Korea, J. Meteorol. Soc. Jpn. Ser. II, 86, 313-333, https://doi.org/10.2151/jmsj.86.313, 2008.

Lee, J., Yoon, J., and Jun, H. D.: Evaluation for the correction of radar rainfall due to the spatial distribution of raingauge network, J. Korea Soc. Hazard Mitig., 14, 337-345, https://doi.org/10.9798/KOSHAM.2014.14.6.337, 2014.

Lee, J.-Y., Kim, W., and Lee, T.-Y.: Physical and dynamic factors that drove the heavy rainfall event over the middle Korean Peninsula on 26-27 July 2011, Asia-Pacific J. Atmos. Sci., 53, 101120, https://doi.org/10.1007/s13143-017-0009-4, 2017a.

Lee, J.-Y., Kwon, M., Yun, K.-S., Min, S.-K., Park, I.-H., Ham, Y.-G., Jin, E. K., Kim, J.-H., Seo, K.-H., Kim, W., Yim, S.-Y., and Yoon, J.-H.: The long-term variability of Changma in the East Asian summer monsoon system: A review and revisit, Asia-Pacific J. Atmos. Sci., 53, 257-272, https://doi.org/10.1007/s13143-017-0032-5, 2017b.

Lee, T.-Y. and Kim, Y.-H.: Heavy precipitation systems over the Korean Peninsula and their classification, J. Korean Meteorol. Soc., 43, 367-396, 2007.

Lee, Y. H., Park, S. K., and Chang, D.-E.: Parameter estimation using the genetic algorithm and its impact on quantitative precipitation forecast, Ann. Geophys., 24, 3185-3189, https://doi.org/10.5194/angeo-24-3185-2006, 2006.

Mass, C.: Topographically forced convergence in western Washington State, Mon. Weather Rev., 109, 1335-1347, 1981.

McGrath, D. and Zhang, C.: Spatial distribution of soil organic carbon concentrations in grassland of Ireland, Appl. Geochem., 18, 1629-1639, 2003.

Milford, J. R. and Dugdale, G.: Estimation of rainfall using geostationary satellite data, in: Applications of Remote Sensing in Agriculture, edited by: Steven, M. D. and Clark, J. A., Butterworth, London, 97-110, 1990.

Moran, P. A. P.: The interpretation of statistical maps, J. Roy. Stat. Soc. B, 10, 243-251, 1948.

Mukhopadhyay, P., Singh, H. A. K., and Singh, S. S.: Two severe Nor'westers in April 2003 over Kolkata using Doppler Radar observations and satellite imagery, Weather, 60, 343-353, 2005.

Nam, J.-E., Lee, Y. H., Ha, J.-C., and Cho, C.-H.: A study on the $e$ folding distance of summer precipitation using precipitation reanalysis data, in: Proc. the Autumn Meeting of Korean Meteorological Society, Korean Meteorol. Soc., 13-15 October 2014, Jeju, Korea, 657-658, 2014.

Okuyama, A., Andou, A., Date, K., Hosaka, K., Mori, N., Murata, H., Tabata, T., Takahashi, M., Yoshino, R. and Bessho, K.: Preliminary validation of Himawari-8/AHI navigation and calibration. Proc. SPIE, 9607, 96072E, https://doi.org/10.1117/12.2188978, 2015.

Ord, J. K. and Getis, A.: Local spatial autocorrelation statistics: distributional issues and an application, Geogr. Anal., 27, 286-306, 1995.

Park, S. K.: Nonlinearity and predictability of convective rainfall associated with water vapor perturbations in a numerically simulated storm, J. Geophys. Res., 104, 31575-31587, https://doi.org/10.1029/1999JD900446, 1999.

Park, S. K. and Lee, E.: Synoptic features of orographically enhanced heavy rainfall on the east coast of Korea associated with Typhoon Rusa (2002), Geophys. Res. Lett., 34, L02803, https://doi.org/10.1029/2006GL028592, 2007.

Rabin, R. M., Corfidi, S. F., Brunner, J. C., and Hane, C. E.: Detecting winds aloft from water vapor satellite imagery in the vicinity of storms, Weather, 59, 251-257, https://doi.org/10.1256/wea.182.03, 2004.

Ritschel, C., Ulbrich, U., Névir, P., and Rust, H. W.: Precipitation extremes on multiple timescales - Bartlett-Lewis rectangular pulse model and intensity-duration-frequency curves, Hydrol. Earth Syst. Sci., 21, 6501-6517, https://doi.org/10.5194/hess-216501-2017, 2017.

Riyu, L., Oh, J. H., Kim, B. J., Baek, H.-J., and Ronghui, H.: Associations with the interannual variations of onset and withdrawal of the Changma, Adv. Atmos. Sci., 18, 1066-1080, https://doi.org/10.1007/s00376-001-0023-3, 2001.

Rodriguez-Iturbe, I., Cox, D. R., and Isham, V.: Some models for rainfall based on stochastic point processes, P. Roy. Soc. Lond. A, 410, 269-288, 1987.

Schiemann, R., Erdin, R., Willi, M., Frei, C., Berenguer, M., and Sempere-Torres, D.: Geostatistical radar-raingauge combination with nonparametric correlograms: methodological considerations and application in Switzerland, Hydrol. Earth Syst. Sci., 15, 1515-1536, https://doi.org/10.5194/hess-15-1515-2011, 2011.

Skøien, J. O., Blöschl, G., and Western, A. W.: Characteristic space scales and timescales in hydrology, Water Resour. Res., 39, 1304, https://doi.org/10.1029/2002WR001736, 2003.

Smith, B. L. and Yuter, S. E.: Water vapor fluxes and orographic precipitation over northern California associated with a landfalling atmospheric river, Mon. Weather Rev., 138, 74-100, https://doi.org/10.1175/2009MWR2939.1, 2010.

Song, H.-J. and Sohn, B.-J.: Two heavy rainfall types over the Korean Peninsula in the humid East Asian summer environment: A satellite observation study, Mon. Weather Rev., 143, 363-382, https://doi.org/10.1175/MWR-D-14-00184.1, 2015.

Stohl, A., Forster, C., and Sodemann, H.: Remote sources of water vapor forming precipitation on the Norwegian west coast at $60^{\circ} \mathrm{N}-$ a tale of hurricanes and an atmospheric river, J. Geophys. Res., 113, D05102, https://doi.org/10.1029/2007JD009006, 2008.

Sun, J. and Lee, T.-Y.: A Numerical Study of an Intense Quasi-stationary Convection Band over the Korean Peninsula, J. Meteorol. Soc. Jpn. Ser. II, 80, 1221-1245, https://doi.org/10.2151/jmsj.80.1221, 2002.

Tompkins, A. M.: Organization of tropical convection in low vertical wind shears: The role of water vapor, J. Atmos. Sci., 58, 529-545, https://doi.org/10.1175/15200469(2001)058<0529:OOTCIL>2.0.CO;2, 2001.

Trenberth, K. E.: Atmospheric moisture recycling: Role of advection and local evaporation, J. Climate, 12, 1368-1381, 1999.

Trenberth, K. E. and Stepaniak, D. P.: Co-variability of components of poleward atmospheric energy transports on seasonal and interannual timescales, J. Climate, 16, 3690-3704, 2003 a.

Trenberth, K. E. and Stepaniak, D. P.: Seamless poleward atmospheric energy transports and implications for the Hadley circulation, J. Climate, 16, 3705-3721, 2003 b.

Velden, C. S.: Satellite observations of Hurricane Elena (1985) using the VAS $6.7 \mu \mathrm{m}$ "watervapor" channel, B. Am. Meteorol. Soc., 68, 210-215, 1987. 
Volkmann, T. H. M., Lyon, S. W., Gupta, H. V., and Troch, P. A.: Multicriteria design of rain gauge networks for flash flood prediction in semiarid catchments with complex terrain, Water Resour. Res., 46, W11554, https://doi.org/10.1029/2010WR009145, 2010.

Yu, X., Park, S. K., Lee, Y. H., and Choi, Y. S.: Quantitative precipitation forecast of a tropical cyclone through optimal parameter estimation in a convective parameterization, Sci. Online Lett. Atmos., 9, 36-39, 2013.
Zeweldi, D. A. and Gebremichael, M.: Evaluation of CMORPH precipitation products at fine space-time scales, J. Hydrometeorol., 10, 300-307, 2009.

Zhou, T.-J. and Yu, R.-C.: Atmospheric water vapor transport associated with typical anomalous summer rainfall patterns in China, J. Geophys. Res., 110, D08104, https://doi.org/10.1029/2004JD005413, 2005. 